ISSN 2693-2504

\title{
Oxygen Homeostasis and Mitochondrial Function in COVID-19 and ARDS Patients: The Ultimate Vital Signs
}

\author{
Journal of Bioscience \& Biomedical Engineering
}

Research Article

Avraham Mayevsky ${ }^{1 *}$, Elhanan Meirovithz ${ }^{2}$

1,2 The Mina \& Everard Goodman Faculty of Life Sciences, Bar-Ilan University, Ramat-Gan 5290092, Israel

\author{
Correspondence author \\ Avraham Mayevsky \\ Professor Emeritus \\ The Mina \& Everard Goodman Faculty of Life Sciences \\ Bar-Ilan University \\ Ramat-Gan 5290002 \\ ISRAEL \\ Tel : 972-544-861854 \\ Fax : 972-3-5351561
}

Submitted : 4 Aug 2020 ; Published : 6 Sep 2020

\begin{abstract}
The leading cause of death from the COVID-19 is the development of Pneumonia and Acute Respiratory Distress Syndrome-ARDS. Advanced physiological monitoring of COVID -19 patients in real time is a missing tool that avoid the optimization of better diagnosis and evaluating the efficacy of the treatment given. As of today, the monitoring of the systemic vital signs provides important information regarding the respiratory and cardiovascular systems including the pulse oximetry that provide data on hemoglobin oxygenation in the macro circulation. Our hypothesis is that the pathophysiology of COVID-19 and ARDS patients includes severe changes in the microcirculatory hemodynamics and cellular disturbances in Tissue and cellular Oxygen Homeostasis. Therefore, we postulate that real time monitoring of mitochondrial NADH redox state and microcirculatory blood flow, volume and hemoglobin oxygenation is the missing information that will affect dramatically the outcome of COVID-19 and ARDS patients. During the last 2 decades we studied the mechanism of blood flow redistribution activated in animal models as well as in patients exposed to total body negative oxygen balance. This mechanism is activated by the sympathetic pathway. This effect is not equal in all organs of the body, namely, in the most vital organs - brain, heart, and adrenal glands oxygen supply is preserved while in the less vital organs (visceral and peripheral organs) hypo perfusion and negative oxygen balance is recorded. In order to evaluate the tissue oxygen homeostasis, we developed a new concept named-LifenLight Score (LLS) ${ }^{T M}$ based on the monitoring of four physiological parameters measured in real time from one of the less vital organs in the body. Our developed device is monitoring mitochondrial function by measuring the NADH auto fluorescence and microcirculatory blood flow, tissue reflectance and hemoglobin oxygenation. In animal model we monitored simultaneously the brain and the small intestine. In patients we used a 3-way Foley catheter introduced to the bladder via the urethra. We found that monitoring the less vital organ could serve as an early warning signal to the development of negative oxygen balance in the body as well as indicate of a recovery process in the improvement of the oxygen balance homeostasis. In conclusion, we hypothesize that using our new monitoring system will be able to detect deterioration process related to hypoxia in COVID-19 and ARDS patients, as well as to monitor improvement in tissue oxygen balance due to various treatments such as exposure to hyperoxia.
\end{abstract}

Keywords: Hemoglobin Saturation, Microcirculation Blood Flow, NADH Redox State, Tissue Oxygen Balance

\section{Introduction}

Preface

During the end of 2019, a new coronavirus associated with severe respiratory disease was reported in Wuhan, China [1]. The patient' arterial blood gas analysis show sign of hypoxemia with oxygen level of $67 \mathrm{mmHg}$. About the same time, another study described the clinical, laboratory and other features of

a group of coronavirus patients in Wuhan, China [2]. Their interpretation was that the "covid-19 infection caused clusters of severe respiratory illness similar to severe acute respiratory syndrome coronavirus and was associated with ICU admission and high mortality". 
In April 2020 Geier and Geier published a very important paper regarding the respiratory conditions in the COVID-19 patients and suggested possible new alternative treatments approach [3]. They joined the conclusion of another group of scientists that "Respiratory conditions in COVID-19 are of such importance that it was described one of the hallmarks of a critical course of COVID-19 is the development of ARDS" [4]. Similar pathological findings of COVID-19 were associated with ARDS [5]. Varga et al. reported that endothelial cell infection and endothelities are part of the COVID-19 disease [6].

Acute Respiratory Distress Syndrome (ARDS) that was described initially in 1967 is a state of reduced oxygen delivery to the various organs in patient [7]. Since then, a very large number of papers were published to describe ARDS distribution in various type of patients, its definition and possible therapeutic options [8-10]. In 2018, Fan et al reviewed the accumulated recent knowledge regarding the ARDS and the advances in diagnosis and treatment[100].

In severe cases of COVID-19 the respiration rate is greater than 30 per minute, the blood oxygen saturation is below $93 \%$ and the ratio $\mathrm{PaO}_{2}: \mathrm{FiO}_{2}$ is below $300 \mathrm{mmHg}$ [11]. The infection is defined by the same scientists and clinicians as critical when one of the 3 following conditions will be developed:

1. Respiratory failure and mechanical ventilation.

2. Shock.

3. Multiple organ failure and admission in the Intensive Care Unit (ICU).

All those criteria are related directly to the decrease in oxygen supply to the patient and therefore the monitoring of oxygen status or levels in the various organs/compartments is critical for the diagnosis as well as the evaluation of treatment efficacy in COVID-19 patients.

As of today, the use of advanced monitoring devices to evaluate the body and tissue oxygen homeostasis is missing in daily clinical practice and especially in COVID-19 patients. The use of pulse oximetry is the sole parameter that diagnose oxygen homeostasis but its real clinical value is very limited in COVID-19 patients as well as in other critical situation such as ARDS. According to our long term experience in monitoring of physiological parameters in experimental animals we are suggesting to add to the standard monitored parameter namely, the systemic vital signs and the Pulse Oximetry, various parameters representing the oxygen homeostasis at the tissue and cellular level as seen in Figure 1.

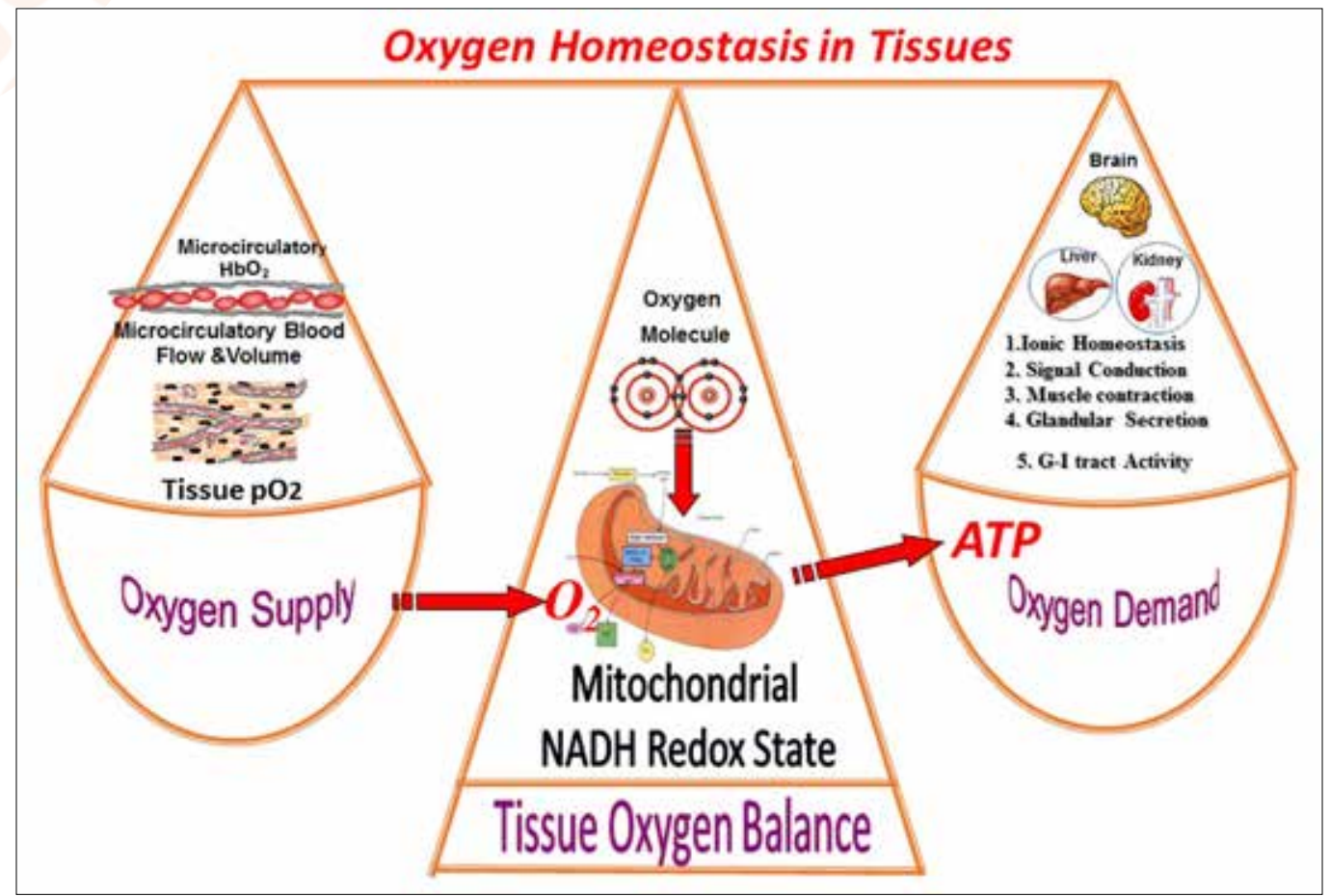

Figure 1: Schematic illustration of the concept Tissue Oxygen Balance. The left side shows the parameters represent the oxygen supply to the tissue and the right side shows the processes determined the demand for oxygen. The triangle in the center represent the tissue oxygen balance evaluated by the mitochondrial NADH redox state.

We will show that tissue oxygen partial pressure is not necessary to be monitored if other oxygenation parameters are monitored as seen in Figure 2 


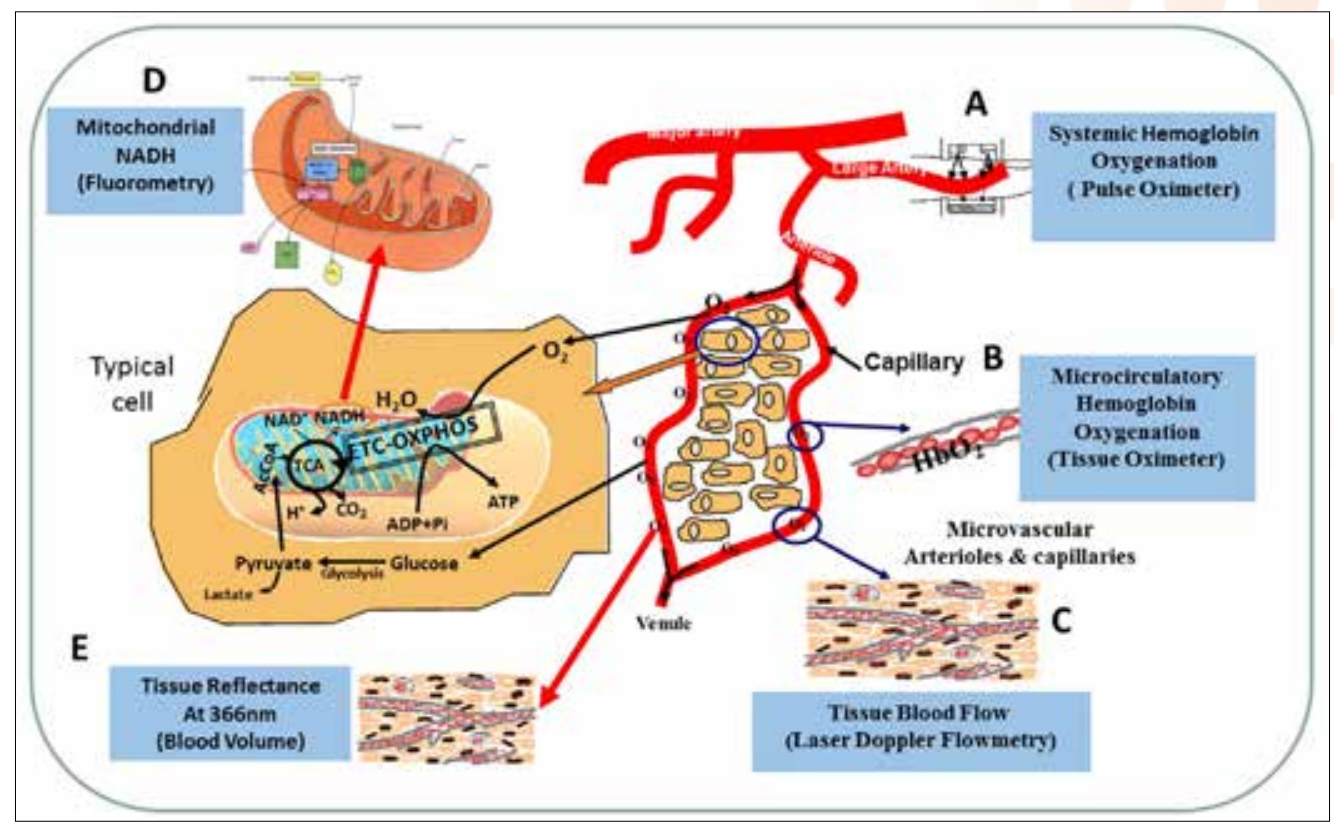

Figure 2: The technology developed for real time evaluation of energy metabolism at the tissue level. Part A shows the coupling between the macro-circulation measured by Pulse oximetry and the microcirculation. B-C - The main monitoring techniques of microcirculatory compartments. D - Monitoring of the intracellular organelle, the mitochondria. E - The total back scattered light reflected from all parts of the tissue.

The aims of the current paper are to answer the following 2 the "Bristol Pneumatic Institute" in 1798 [20]. major questions:

1. What are the additional optimal parameters to be monitored in the COVID-19 patient?

2. What is the best site in the body, of those patients, to locate the monitoring sensor(s).

\section{Historical Background}

Oxygen Metabolism

Two historical discoveries made in the 18th and 19th centuries led to our current understanding of the processes involved in the intracellular respiration providing the majority of ATP needed for cellular functions. The first event occurred about 250 years ago (1771- 1775) when Oxygen was discovered by three scientists namely, Carl Wilhelm Scheele, Joseph Priestley and Antoine de Lavoisier. The second event was around 110120 years later by Richards Altman and Carl Benda that discovered the Mitochondria [12,13]. It took another 60-70 years of intensive research of the mitochondria to conclude that $90-95 \%$ of the consumed molecular oxygen by the organism is utilized by the cytochrome oxidase acting at the final step in the oxidative phosphorylation process performed by the respiratory chain located in the mitochondria [14-18]. The rest of the consumed $\mathrm{O}_{2}$ is utilized by other oxidases such as the tyrosine hydroxylase converting the tyrosine to DOPA in the synthesis of Dopamine in the brain [19]. Although the understanding of the exact mechanism of oxygen utilization by the mitochondria occurred in the middle of the $20^{\text {th }}$ century, the use of oxygen in respiratory therapy was initiated by the physician Thomas Beddoes and the inventor James Watt towards the end of the $18^{\text {th }}$ century (1794-1798). The technology to generate oxygen and other gases enabled to open the first oxygen therapy site,

Now I would like to discuss the processes of Oxygen Uptake, Transport by the blood and Utilization by the Mitochondria in healthy and sick patients. Those processes are the building stones of the basic concept named Tissue Oxygen Balance that keep the homeostasis of oxygen in the body. The concept of "Physiological Homeostasis" that was coined by Cannon in 1929 was based on the general idea of Claude Bernard in 1878 that the organism is keeping the internal environment stable $[21,22]$. One of the critical element in the body is the homeostasis of oxygen that should be kept stable. It means that tissue oxygen balance that represents the relationship between oxygen supply and oxygen demand will vary in a narrow range. Figure 1 demonstrates the homeostasis of oxygen in a typical tissue. Oxygen demand (right side) is determined by the specific physiological processes that consume oxygen in the various organs of the body. In all organs the main energy source is ATP synthetized in the mitochondria. The basic processes involved in oxygen supply and its regulation (left side) are very similar in all organs of the body and the details will be discussed later. This concept- oxygen homeostasis in the brain was investigated at the end of the 19th century and was published by Roy and Sherrington in 1890 [23]. They studied the effect of various factors on the regulation of blood flow to the brain and came to the following conclusion:

"We conclude then, that the chemical products of cerebral metabolism contained in the lymph which bathes the walls of the arterioles of the brain can cause variations of the caliber of the cerebral vessels: that in this reaction the brain possesses an intrinsic mechanism by which its vascular supply can be varied locally in correspondence with local variations of functional 
activity". The interpretation of their conclusion is that, in the brain, changes in oxygen consumption due to changes in functional activity are due to variations in blood vessels diameter. The next step in the development of the concept Oxygen Balance Homeostasis was made by the leading English physiologist J. Barcroft that published the book "The Respiratory Function of Blood" in 1914 [24]. In Chapter XI of the book he discussed the subject of "The call for Oxygen by the tissues". He proved that "There is no instance in which it can be proved that an organ increases its activity, under physiological conditions, without also increasing its demand for oxygen. Barcroft came to the second conclusion that "in no organ excited by any form of stimulus can it be shown that positive work is done without the blood supply having to respond to a call for oxygen".

It is important to remember that Oxygen is a drug that may need to be optimized in the level given to patients thus avoiding under as well as overdosing $[25,26]$.

\section{Mitochondrial function}

As seen in Figure 1, the mitochondrial NADH redox state represents the tissue oxygen balance. The discovery of the intracellular organelle-mitochondrial happened toward the end of the 19th century by Altmann in 1890 and Benda in 1898 [12,13]. Its involvement in representing the tissue oxygen balance was formulated only close to 100 years later $[27,28]$. At this stage we were able to monitor simultaneously, microcirculatory blood flow, blood volume, hemoglobin oxygenation and mitochondrial NADH redox state. As we know today the best monitored parameter that represents mitochondrial function in vivo is the redox state of NADH, therefore I will describe in this section the historical background of its monitoring under in vivo conditions.
Chance et al in 1973[101] review the historical studies that made the connection between the activity of mitochondria and oxygen utilization as follows: "The accumulation of evidence since the pioneer work of Otto Warburg an "Atmungsferment " and David Keilin on cytochromes, as the keystones of cellular oxygen utilization led us to the study of the redox states of electron carriers in isolated mitochondria as a function of oxygen concentration and to develop techniques to measure the states of anoxia and normoxia in living tissues" [29,30].

During the early 1950s the study of mitochondrial activity in vitro and after 10 years in vivo, was accelerated by the development of new optical monitoring devices. The UV-A light was applied to measure NADH absorption and later on the measurement of NADH fluorescence was started [31-36]. During those years a large number of papers on the monitoring of NADH were published from the laboratory of Prof. B. Chance and he became the leader of in vitro and in vivo monitoring of NADH fluorescence.

The detailed descriptions of the respiratory chain and oxidative phosphorylation in the mitochondria - published in 1955 by Chance \& Williams, established our basic knowledge of the mitochondrial function [37-40]. In those five papers, Chance and Williams defined, for the first time, the metabolic states of isolated mitochondria in vitro, depending on the substrate, oxygen and ADP levels. In addition, they correlated those metabolic states to the oxidation-reduction levels of the respiratory enzymes as seen in Figure 3. The physiological significance of those metabolic states was discussed in 1956 by Chance \& Williams [41]. Detailed explanation of the table will be given later in this paper.

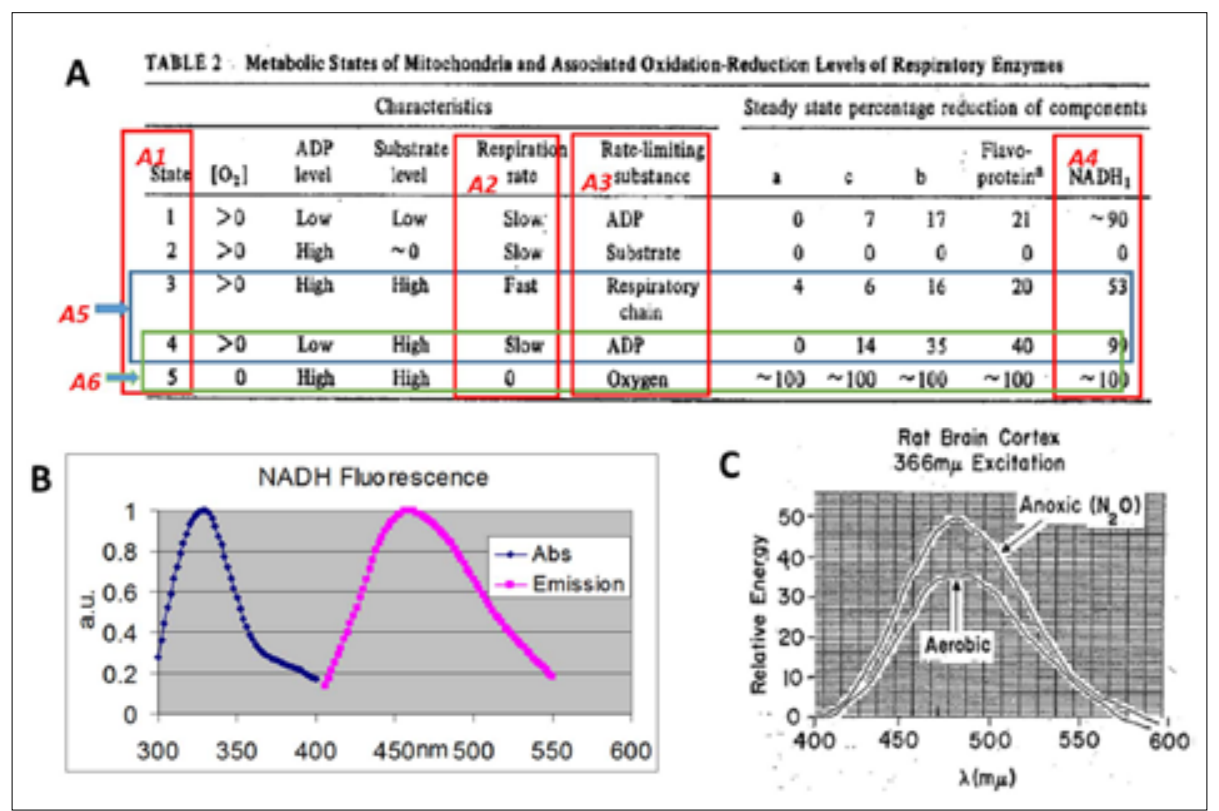

Figure 3: A - Mitochondrial metabolic state, defined in vitro, by Chance and Williams, and opened up a new era in measurements of respiratory chain enzyme's redox state in vitro as well as in vivo. B - Absorption and emission spectra of NADH illuminated by UV light. C - The emission spectra of rat cerebral cortex under aerobic conditions (lower trace) and under anoxic conditions (upper trace). 
An intensive use of the real time in vivo NADH monitoring approach started in 1962. The "classical" paper on in vivo monitoring of NADH was published in 1962 by Chance et al. [42]. They were able to simultaneously monitor the brain and kidney of anesthetized rats using two microfluorometers. Chance and collaborators elaborated on this kind of in vivo monitoring and used it in other rat organs [43-46].

The next section will provide the basic facts and knowledge regarding the basic physiology of oxygen supply to tissues and its utilization by the mitochondria.

\section{Principles of Real Time Monitoring Options Oxygen metabolism}

Since $90-95 \%$ of the total body consumed oxygen is utilized in the mitochondria, it is important to understand its gradient from the atmospheric air (the source) to the site of utilization in the mitochondria. Figure 4

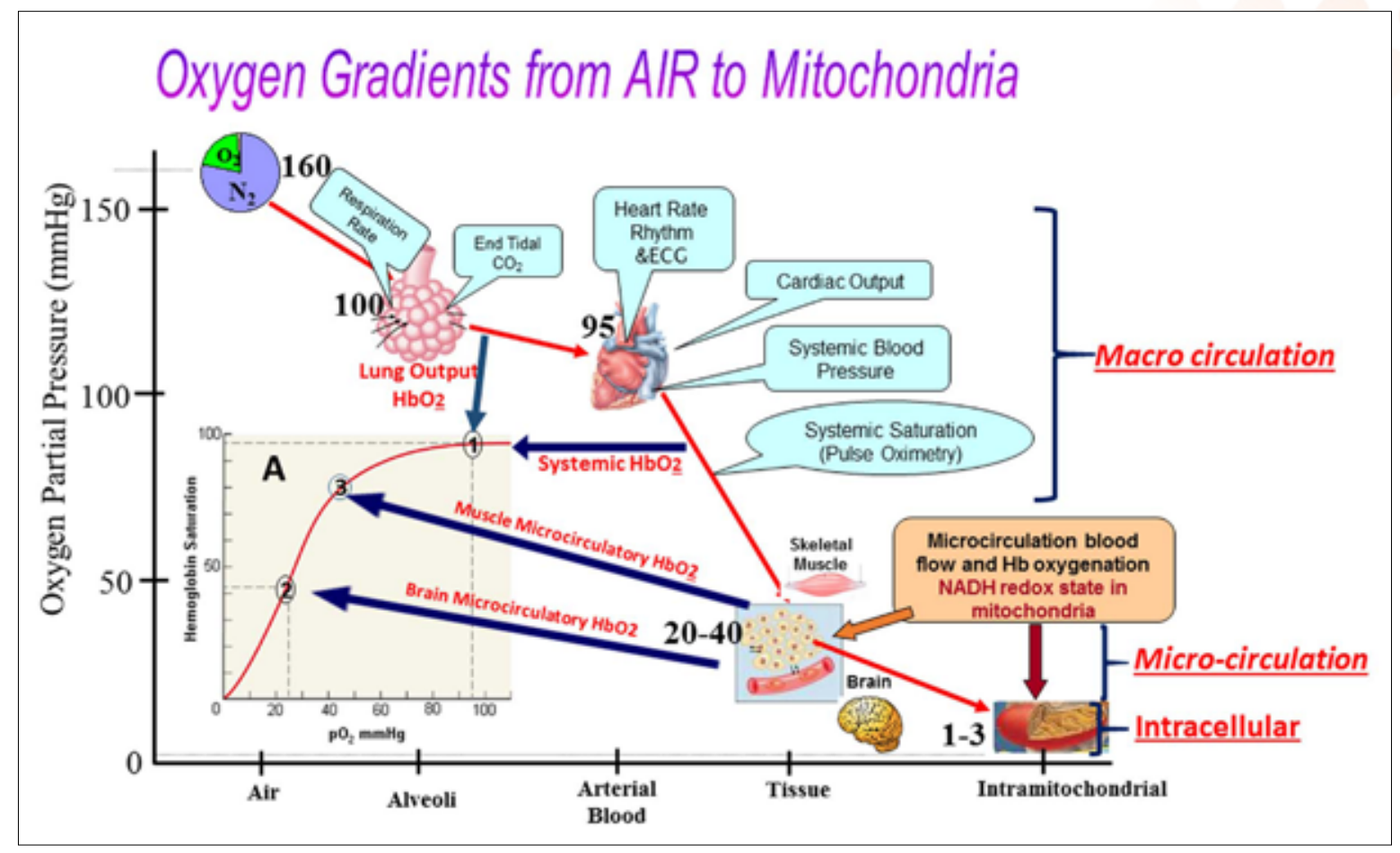

Figure 4: The gradient of $\mathrm{O}_{2}$ from atmospheric air to the mitochondria in a typical organ in the body. Monitoring of patients include various parameters shown along the oxygen gradient. In the insert $\mathrm{A}$, the dissociation curve of $\mathrm{O}_{2}$ and hemoglobin is presented and 3 arrow are pointing to specific oxygenation levels. The three main monitored body compartment are seen in the right side of the figure.

In Figure 4 the decreased level of oxygen is illustrated in the main sites between air and the mitochondria. In insert A, the association/dissociation curve of hemoglobin $\left(\mathrm{Hb} / \mathrm{HbO}_{2}\right)$ is presented. Under normal conditions, the blood collected from the various organs of the body is re-oxygenated in the alveoli of the lungs that are surrounded by blood capillaries. The oxygenated arterial blood $\left(\mathrm{HbO}_{2}=97-98 \%\right.$ saturation $)$ reached the left ventricle of the heart and distributed to all organs of the body via the arterial macro circulation part of the blood system. The systemic oxygenated blood is shown also in insert A part 1. It's important to note that the release or download of oxygen from of oxygenated hemoglobin is possible only by passive diffusion process dependent on the oxygen gradient across the blood vessels and the extracellular and intracellular spaces. Therefore, most of the oxygen will be provided to the cellular compartment of the various organs via the microcirculation and not the macro-circulation as seen in the lower right part of Figure 4. The level of $\mathrm{HbO}_{2}$ saturation in the microcirculation of the various organs is dependent on the blood flow to the organ and the rate of oxygen consumption by the specific tissue. For example, in skeletal muscle at the resting state, the saturation (around $80 \%$ ) is much higher (Fig. 4A3) as compared to the resting brain (40-50\%) seen in point 2 in the figure. The reason is that the "resting" brain consumes much more oxygen as compared to the muscle and the download of oxygen from the $\mathrm{HbO}_{2}$ is much higher.

The main approaches to monitor oxygen metabolism under in vivo conditions and in real time are to measure oxygen levels in the tissue and the $2^{\text {nd }}$ way is to measure hemoglobin saturation. 2.2 Monitoring of partial pressure of oxygen $\left(\mathrm{pO}_{2}\right)$ using surface or tissue penetrating microelectrodes.

The development of oxygen sensitive electrode was initiated between the end of the 19th and the beginning of the 20th centuries. The R\&D process led to the development of oxygen microelectrodes that were used in studying photosynthesis in 1938, and later on in animal tissues [47-49]. Bronk used the oxygen microelectrodes in studying the cerebral cortex of experimental animal and patients during operations [50]. Various companies had developed commercial electrodes that are used today in animal experiments as well as in clinical application. The main problem in using penetrating microelectrodes inside a tissue is the anatomical damage of 
the functioning tissue and the creation of artificial damagedtissue around the tip of the electrode that may not represent the real oxygen level in the healthy monitored tissue. In order to avoid this damage, we used electrodes that were located on the surface of the brain, for example, and the damage to the organ was minimal. A very detailed review on partial pressure of oxygen in the human body was published in the last years [51-53].

We developed a multiparametric system that will enable us to correlate between brain $\mathrm{pO}_{2}$ and mitochondrial $\mathrm{NADH}$ fluorescence as seen in Figure $5 \mathrm{~A}$.

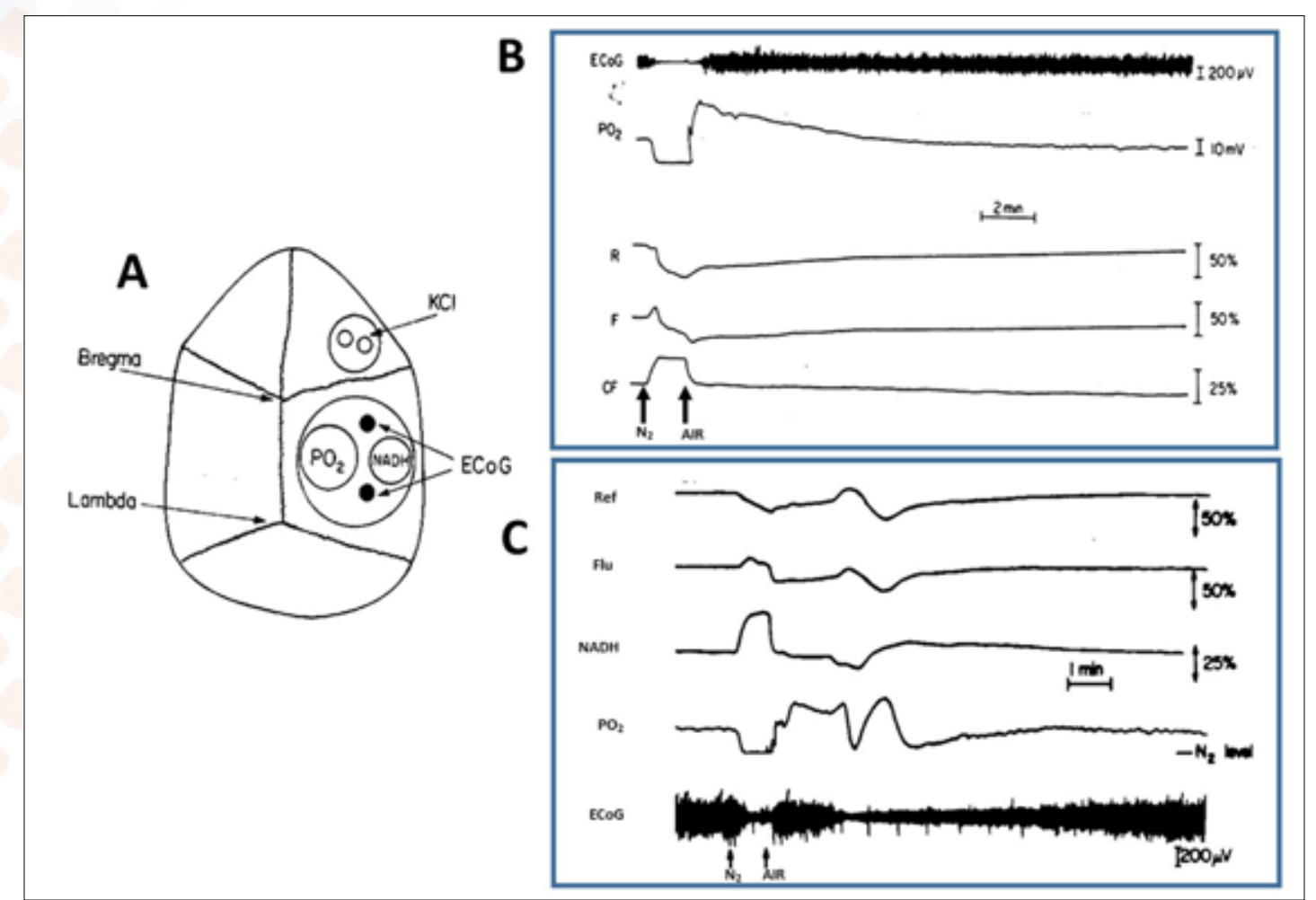

Figure 5: A - Topical view of the skull and brain of a small animal (rat or gerbil). In this model the monitored parameters are partial pressure of oxygen, mitochondrial NADH and electrical activity (ECoG). B and C - Effects of anoxia $\left(\mathrm{N}_{2}\right)$ on metabolic and electrical activities in the rat brain. ECoG, electrocorticogram; $\mathrm{pO}_{2}$-partial pressure of oxygen, 366-nm reflectance; F, 450$\mathrm{nm}$ fluorescence; CF, 450-nm corrected fluorescence

We monitored brain $\mathrm{pO}_{2}$, using a surface electrode, together with the monitoring of mitochondrial NADH redox state and electrical activity (ECoG) in rats and gerbils [54-56]. The electrodes were constructed inside $1.6 \mathrm{~mm}(\mathrm{OD})$ polyethylene tubing (PE-160). Platinum wire (25 micro meters) was sealed in glass by a flame, and an insulated lead wire was attached to the other end of the platinum wire. Two assemblies, along with Teflon-coated 250-micron silver wire (for use as a reference) were pulled into the PE tubing so that the glass-sealed ends of the platinum were flush with the end of the PE tubing. The Teflon on the end of the silver wire was removed, and this bare section could extend beyond the edge of the PE tubing. The electrode's zero response was tested in saline bubbled with $\mathrm{N} 2$, and its linearity was tested in saline bubbled with different mixtures of $\mathrm{O}_{2}$ and $\mathrm{N}_{2}$. A cellulose diacetate membrane was put on the tip by dipping the electrode in $5 \%$ cellulose diacetate solution. The calibration and calculation of $\mathrm{pO}_{2}$ in the brain are only a relative term, since the absolute value of $\mathrm{pO}_{2}$ is very sensitive to the electrode location on the brain. Spontaneous electrical activity of the brain surface $(\mathrm{ECoG})$ was measured by two polished stainless steel rods or silver wire inserted into the MPA.
Male gerbils (60-70 g) were used in our study. The animal was anesthetized by intra-peritoneal injection of Equithesin (a mixture of pentobarbital, chloral hydrate, magnesium sulfate) $0.3 \mathrm{ml} / 100 \mathrm{~g}$. The skull was exposed by a midline incision and a 5-6 $\mathrm{mm}$ diameter hole was drilled in the parietal bone to fit a combined NADH-pO, cannula (Fig. 5A). A 2 mm diameter hole was drilled in the frontal bone to fit a push-pull cannula for epidural application of $\mathrm{KCl}$ in order to elicit cortical SD. Two stainless steel screws were implanted on the left parietal bone for holding the cement to the skull. The cannulae and the screws were cemented to the skull by dental acrylic cement. Oxidation-reduction state of NADH was monitored using a standard DC fluorometer/reflectometer with a $1.5 \mathrm{~mm}$ diameter, Y-shape light guide.

It is important to note that oxygen electrode readings are averaging the oxygen level in the vascular, extracellular and intracellular compartments. Figure 5B shows a typical response of the brain to complete anoxia and recovery to the pre-anoxic state. The first response to the $\mathrm{N}_{2}$ breathing is the drop in $\mathrm{pO}_{2}$ to its minimal level $(0)$, which recovered as soon as air was introduced into the breathing mixture. A large overshoot in the 
$\mathrm{pO}_{2}$ was recorded followed by a slow recovery to the normoxic level. In parallel to the $\mathrm{pO}_{2}$ changes, the Intramitochondrial NADH (CF signal) also responded very quickly to anoxia. The high steady level of NADH during the anoxia is in parallel to the very low level of the $\mathrm{pO}_{2}$. During the recovery phase the NADH (CF) reached the normoxic state quickly, while the reflectance and the uncorrected fluorescence recovered more slowly in parallel to the slow recovery in the $\mathrm{pO}_{2}$ trace.

A second response of this setup are presented in Figure 5C. The response to anoxic episode is typical to the lack of oxygen, namely, a sharp drop in $\mathrm{pO}_{2}$ and a large increase in NADH. One minute after breathing air was started, a response similar to the development of Cortical Spreading Depression was recorded. In the $\mathrm{pO}_{2}$ trace a biphasic response was recorded inversely related to the reflected light changes, namely, that when the reflectance showed an increase, the $\mathrm{pO}_{2}$ trace showed a parallel decrease; and when the reflectance showed a large decrease (increased blood volume) the $\mathrm{pO}_{2}$ showed three-to four-fold increase, and then gradually recovered to the normoxic level in parallel to the gradual increase in the reflected light. The biphasic response in the $\mathrm{pO}_{2}$ trace is in correlation to the response of the $\mathrm{NADH}$ fluorescence trace and we assume that it is the typical response to CSD, as described previously after anoxic cycle [57]. The ECoG reached the isoelectric state about $30 \mathrm{~s}$ after breathing $\mathrm{N}_{2}$ and was followed by a fast recovery after rebreathing air.

\section{Measurement of hemoglobin saturation level $\left(\mathrm{HbO}_{2}\right)$ in the macro or micro circulatory blood vessels.}

Two closed blood vessels systems are providing oxygen and nutrients and remove the $\mathrm{CO}_{2}$ and wastes to and from the various cells in the body in order to keep the homeostasis. In the large circulatory system, the blood, arrived oxygenated from the lungs, is flowing from the left side of the heart to all organs in the body and the deoxygenated blood is flowing back via the right side of the heart to the 2 lungs in order to load oxygen and release the $\mathrm{CO}_{2}$ in the lungs. Those activities are taking place in the capillary region that are major parts of each organ in the body. The driving force that distribute the blood in the cardiovascular system is the pumping activity of the left ventricle that, in each systolic contraction, create the systolic blood pressure of $120 \mathrm{mmHg}$. At the end of the diastole, the BP fall down to the zero level range in the left ventricle as seen in Figure $6 \mathrm{~A}$ in the left side.

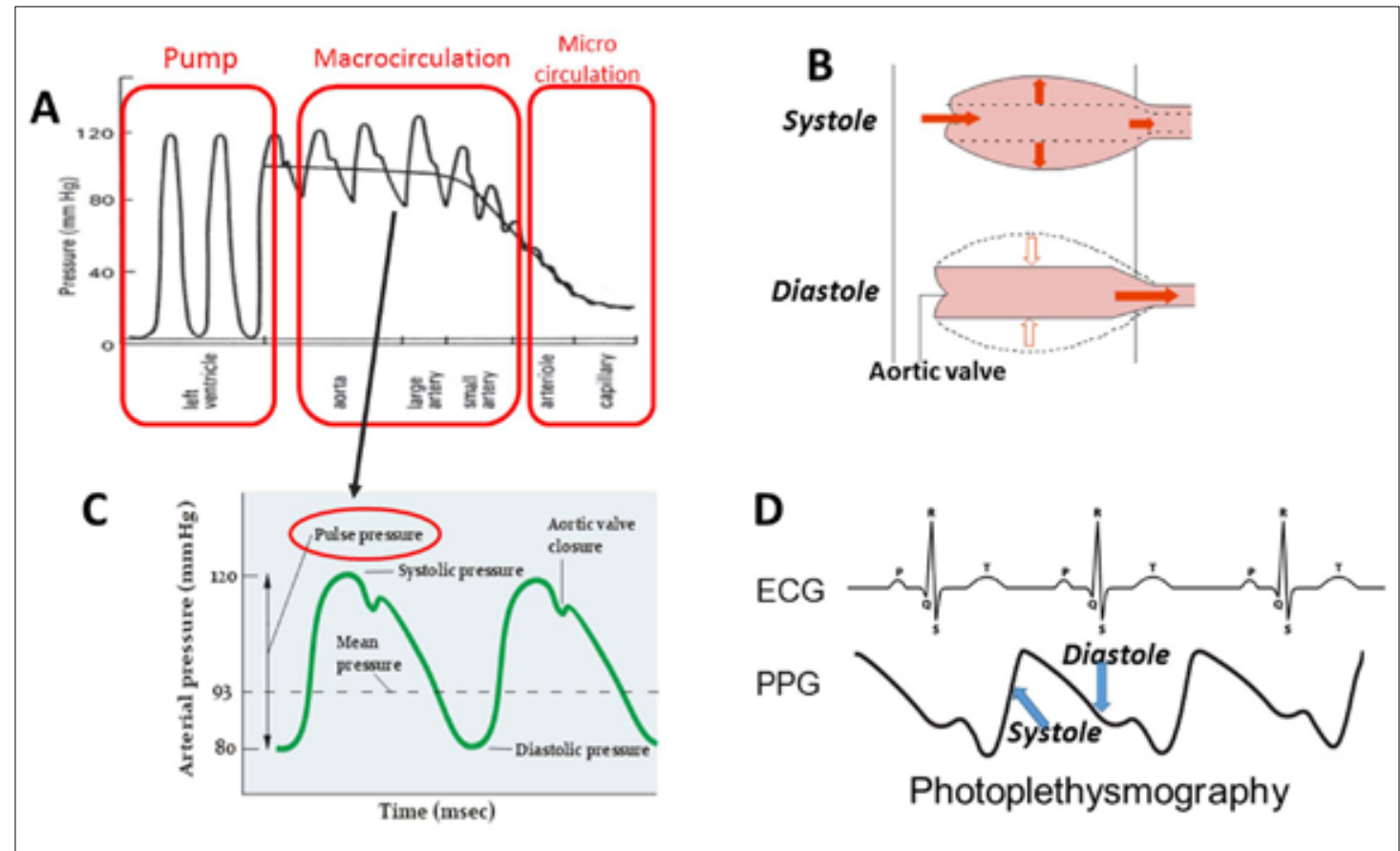

Figure 6: A - schematic presentation of Blood pressure values recorded in various sections of the systemic circulatory areas. B Changes in the volume of blood measured in the aortaduring systolic and diastolic states. $\mathrm{C}$ - The blood pressure wave measured in the macro circulation section. $\mathrm{C}$ - recording of the ECG (electrocardiogram) and the volume changes PPG waves.

From the left ventricle (the pump), the blood is flowing through the aorta that is the initial component of the macro circulation and the pressure is $120 \mathrm{mmHg}$ at the end of the systole decreasing to $80 \mathrm{mmHg}$ at the end of the diastole. Each heartbeat injects the stroke volume from the left ventricle to the aorta that contained elastic fibers in the wall. Part of the stroke volume $(50 \%)$ is flowing through the aorta to the various arteries that provide blood to all organs in the body. The other $50 \%$ of the stroke volume remains in the aorta by stretching the elastic wall during the systole as seen in Figure 6B. During the diastole of the heart (6B lower part), the excess of blood in the aorta is flowing out and the aorta recover to its regular dimensions. This mechanism is keeping a continuous blood flow (rather than pulsatile) from the aorta to the entire arterial system. The difference between the systolic and the diastolic pressure, $120-80 \mathrm{mmHg}$, is called the "Pulse Pressure" that in this case $\mathrm{PP}=40 \mathrm{mmHg}$. The value of the PP is decreasing in the small arteries and is almost undetected in the arterioles and J B \& Bio Engine; $2020 \quad$ www.unisciencepub.com Volume 1 Issue 3 
disappearing in the capillary beds. As seen in Figure 6A the PP is detected and could be recorded in the Macro circulation but not in the Microcirculation. It's important to note that the exchange of majority of oxygen and carbon dioxide between the blood vessels and the extracellular space in the tissues is possible mainly in the capillary bed and very limited in the small arterioles. The diffusion of oxygen from the capillaries to the mitochondria is dependent on the gradient of oxygen between the microcirculation and the mitochondria [58].

The elastic property of the arterial wall was investigated and published by Roy already in 1881 [59].

\section{$\mathrm{HbO}_{2}$ saturation in the macro circulation}

The existence of a pulse pressure wave in the arteries was recognized to provide relevant diagnostics information in patients and led to the development of patients' monitoring devices. In 1937, Hertzman described an optical device that enabled the measurement of changes in volume of blood in various tissues in vivo $[60,61]$. This technology based on the Plethysmography principle ("recording of an Increase") received the name Photo plethysmography (PPG) when light was used. In 2007, John Allen published a topical review that summarizes the background and the applications of the PPG in clinical practice [62]. Figure 6D shows schematic recording of the PPG as compared to the ECG heart beat waves. The main usage of the PPG was in the development of the pulse oximetry as a noninvasive technique to monitor arterial oxygen saturation of hemoglobin [63-68]. Since this measurement of pulse oximetry is based on the analysis of the pulse pressure waveform seen in Figure 6C, it's clear that the measurement is originated from arteries that are large enough and display the pulse pressure wave due to the availability of elastic fibers in its wall. Small arterioles and capillaries that doesn't contain elastic fibers, will not contribute to the PPG signal in the measurement of the pulse oximeter. Therefore, pulse oximetry that display the $\mathrm{HbO}_{2}$ saturation is representing a hemodynamic event occurred in the Macro Circulation and not in the Microcirculation.

Due to the better understanding of the nature of the PPG signal and the new techniques in data analysis, many scientists studied the ability to extract more physiological parameters from the PPG waveform in addition to the pulse oximetry and the heart rate. Allen suggested the following physiological measurements based on published papers: blood pressure, cardiac output, respiration, endothelial function and venous assessment of insufficiency [62].

The main disadvantage of the pulse oximetry technology is its limitation in monitoring of $\mathrm{HbO}_{2}$ saturation during oxygen therapy that includes the exposure of patients to hyperoxic conditions. Under those conditions, it's possible to rely on blood gas analysis after invasive sampling of blood from the patients. Scheeren et al. suggested a new tool -the oxygen reserve index (ORI) to be used during oxygen therapy but this approach should be tested and verified in the perioperative settings as well as in the ICUs [69].

\section{$\mathrm{HbO}_{2}$ saturation in the microcirculation}

Since it is not possible to monitor hemoglobin saturation level in the microcirculation using the pulse oximetry principles we adopted and tested two other possible approaches based on the difference in light absorption by the oxyhemoglobin and the deoxyhemoglobin as seen in Figure 7B. The difference between the 2 absorption spectra in the range of $500 \mathrm{~nm}-650$ $\mathrm{nm}$ is very dramatic and therefore it's very practical to use them in animal studies as well as in clinical daily use. One approach is to measure the entire Hemoglobin spectrum using a reflectance mode and calculate the oxygenation level as was done by Frank et al in 1989 as seen in

Figure 7A [70].

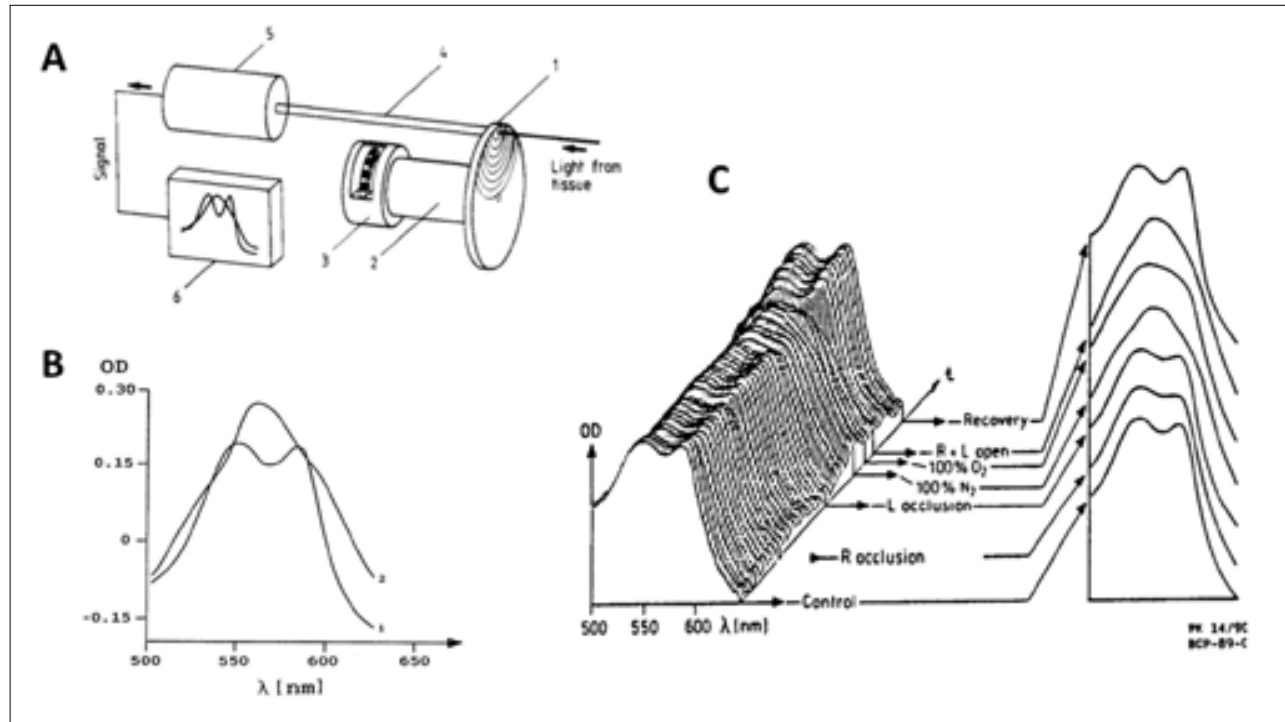

Figure 7: A - Schematic drawing of the EMPHO I detection device. 1: Interference band pass filter disk. 2: micro motor. 3: detection wheel. 4: fluid light guide. 5: photomultiplier tube. 6: computer screen (Reference 61). B - Typical oxygenated (1) and deoxygenated (2) $\mathrm{Hb}$ spectra measured in vivo in a gerbil brain. $\mathrm{C}$ - Sequence of $\mathrm{Hb}$ spectra measured in the gerbil brain exposed to ischemia and anoxia (Mayevsky et al. 1992). 
Figure $7 C$ presents a display of the spectra $(500-650 \mathrm{~nm})$ accumulated in real time from the brain of a gerbil exposed to unilateral and bilateral carotid artery occlusion as well as complete $\mathrm{O}_{2}$ deprivation (breathing $100 \% \mathrm{~N}_{2}$ ). The right side of the figure presents a typical spectrum of the various steps of the perturbation as well as the recovery. During the recovery period the brain was more oxygenated as compared to the $\mathrm{HbO} 2$ level measured during the control period, probably due to the hyperemia produced [71].

We used the same technology called EMPHO I in combination of other physiological parameters measured from the surface of the gerbil brain $[72,73]$.

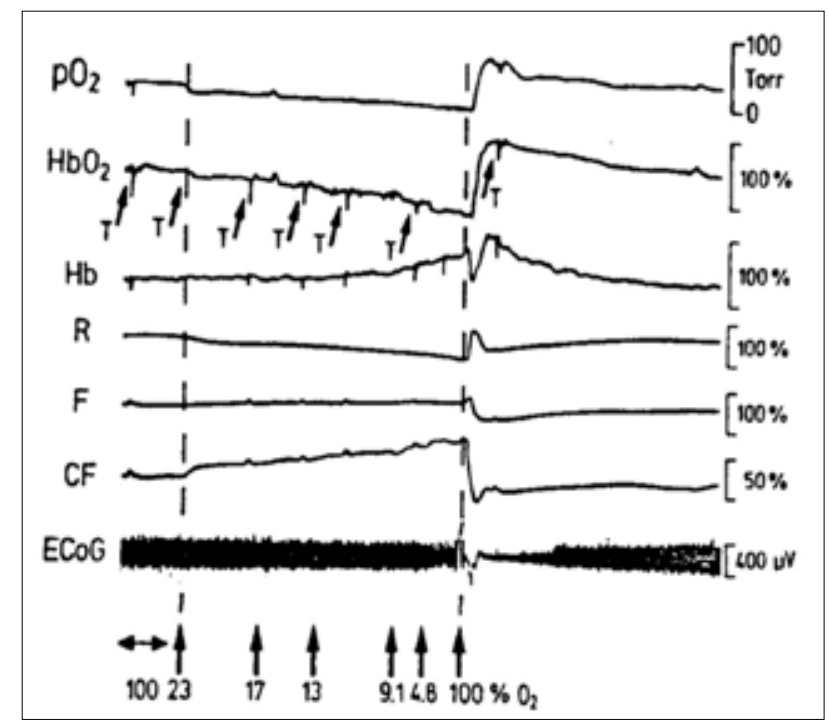

Figure 8: Responses of the gerbil brain to graded hypoxia by lowering the $\mathrm{FiO}_{2} \cdot \mathrm{pO}_{2}$ - tissue oxygen levels, $\mathrm{HbO}_{2}$ oxygenated hemoglobin, $\mathrm{Hb}$ - deoxygenated hemoglobin, $\mathrm{R}, \mathrm{F}$ and $\mathrm{CF}$ - reflectance, fluorescence and corrected fluorescence of NADH. ECoG - electrocorticography.

Figure 8 shows a similar type of response to $\mathrm{O}_{2}$ deprivation was recorded when a gerbil was exposed to systemic hypoxia, as seen in Figure 8. In order to verify the correlation between $\mathrm{HbO}_{2}$ and NADH redox state we added to the monitoring system (in a few of the experiments) an oxygen electrode to measure the tissue average oxygenation level, and a typical response to hypoxia, using this system, is shown. The level of $\mathrm{O}_{2}$ was decreased (in steps) in the breathing mixture from $100 \%$ to $0 \% \mathrm{O}_{2}\left(100 \% \mathrm{~N}_{2}\right)$, and then returned to $100 \% \mathrm{O}_{2}$. As seen, the three indicators of oxygen supply levels changed during the hypoxia and were correlated to each other. The gradual decrease in $\mathrm{O}_{2}$ delivery, as seen in the $\mathrm{HbO}_{2}$ and the $\mathrm{CF}$ traces, had a very small effect on ionic homeostasis. Only a small increase in extracellular $\mathrm{K}+$ was noted during most of the hypoxia episode (results are not presented). The ECoG trace showed changes only when $\mathrm{FiO}_{2}$ was below $5 \%$.

Toward the end of the hypoxia a wave of depolarization was propagated to the rest of the hemisphere during the reoxygenation period of the brain. It can be considered as a wave of spreading depression (SD) developed by an intrinsic factor. The depolarization which occurred during the hypoxia led to a large decrease in blood volume, as seen by a transient decrease in the $\mathrm{Hb}$ trace and a large increase in the $\mathrm{R}$ trace reported by us previously [74]. The SD wave slowed the ECoG recovery as well as leading to an oxidation wave of the NADH redox state due to ion movement. The effects of repetitive cycles of SD on the various parameters are shown in Figure 9. A special push-pull surface cannula was located epidurally 2-3 mm anterior to the MPA (seen in Fig. 5) and was cemented to the skull. The SD wave was initiated by a $0.5 \mathrm{M}$ $\mathrm{KCl}$ epidural application and was stopped by washing the dura with physiological saline.

As seen on line $\mathrm{A}$, the $\mathrm{HbO}_{2}$ trace shows an initial decrease in oxygenation followed by a larger and longer increase. The same biphasic response can be seen in the reflectance trace (R). The NADH redox state trace $(\mathrm{CF})$ shows the typical symmetrical oxidation wave, well correlated to the high activity of the $\mathrm{Na}^{+}$, $\mathrm{K}^{+}$-ATPase keeping the ion gradient recovery after the large depolarization induced by the spreading depression. The same responses were recorded when the second and third waves passed below the MPA, as seen in lines B and C (Fig. 9).

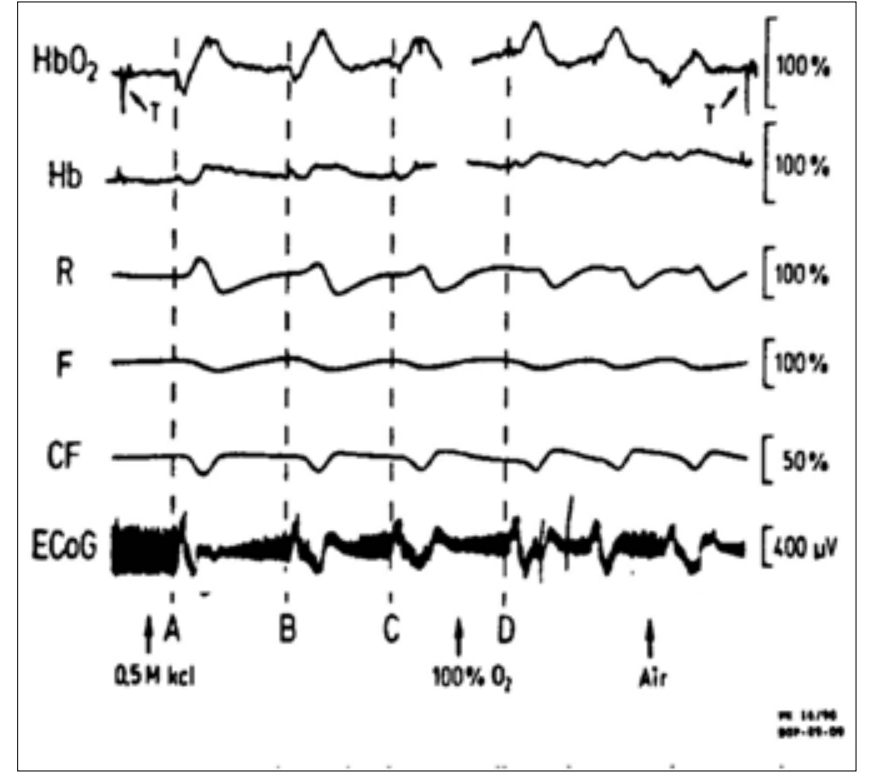

Figure 9: Effects of cortical spreading depression on the metabolic and electrical activities in the gerbil brain. The gerbil was breathing air and then switched to $100 \%$ oxygen. After sign D the air was returned.

The main difference between the three cycles developed under normoxia was the diminution of the initial decrease of the $\mathrm{HbO} 2$ levels, which could also be seen when the waves were induced under hyperoxic condition (D).

\section{Tissue Vitality Monitoring System (TVMS)}

The second approach to monitor $\mathrm{Hb}$ oxygenation in the microcirculation is to measure the reflected light in 2 selected points in the $\mathrm{Hb}$ absorption spectrum described in details by Rampil et al, and later on by our group [28,75]. This developed technology was part of a new multiparametric monitoring 
system developed in our laboratory.

In order to assess the hemodynamic and metabolic functions of the cerebral cortex, we used the Tissue Vitality Monitoring System (TVMS) that includes a combined two devices: a time-sharing fluorometer-reflectometer (TSFR) for mitochondrial $\mathrm{NADH}$ redox state and microcirculatory hemoglobin oxygen saturation $\mathrm{HbO} 2$ measurement combined with a laser Doppler flowmeter (LDF) for CBF monitoring (Fig. 10)[28].

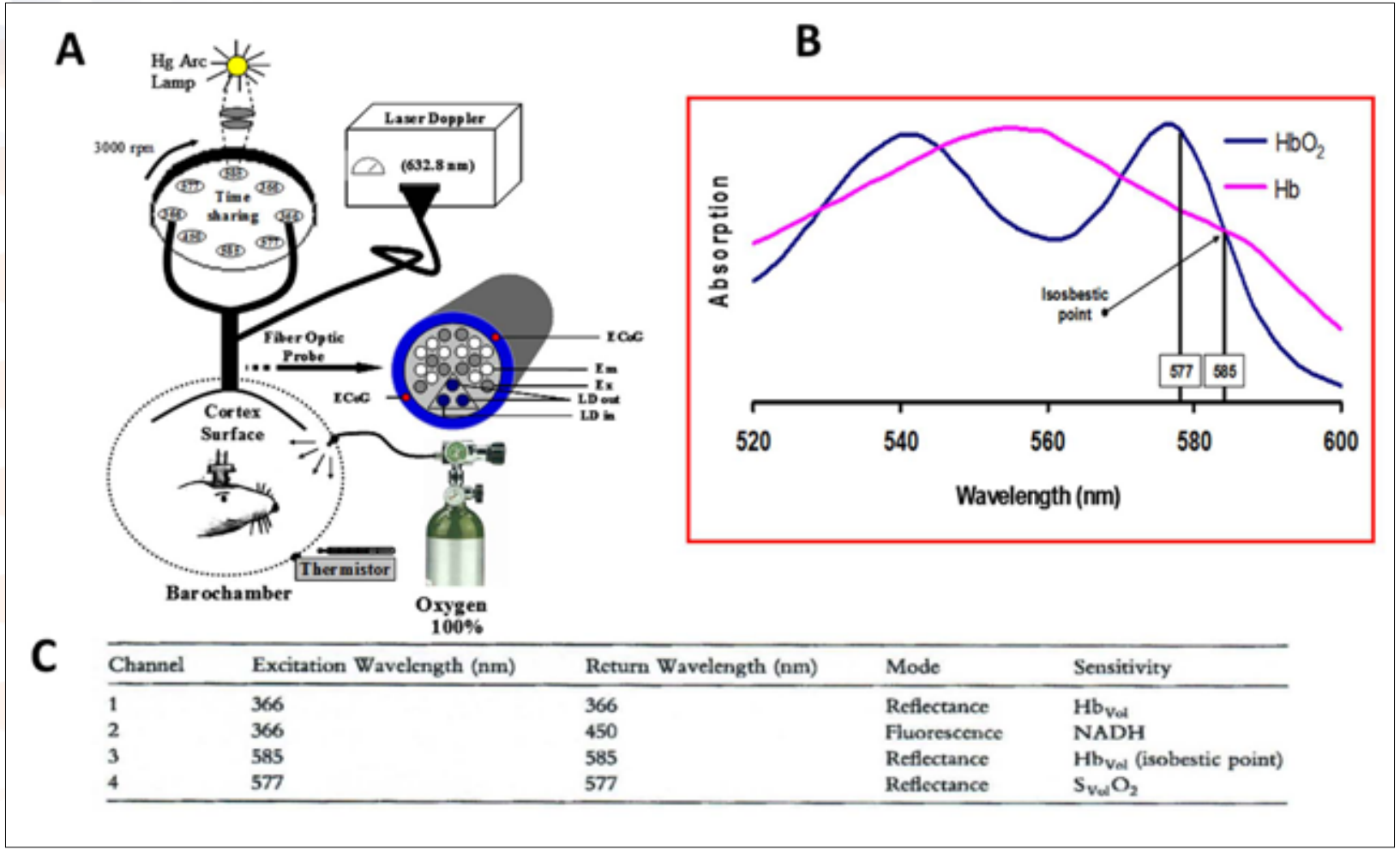

Figure 10: A - Schematic representation of the hyperbaric experimental setup showing the time-sharing fluorometer reflectometer, laser Doppler flowmeter and electrodes for electrocorticography (ECoG). Ex and Em - excitation and emission fibers for NADH and $\mathrm{HbO}_{2}$ monitoring, respectively; LDin and LDout - optical fibers for blood flow monitoring. The numbers in the spinning disk refer to the wavelength filters as seen in the table presented in part $\mathrm{C}$. The rat brain is connected to monitoring system via a flexible fiber optic probe penetrating the wall of the hyperbaric chamber. Part B shows the 2 points in the Hb absorption spectra used to measure the $\mathrm{Hb}$ oxygenation level.

\section{Hemoglobin Oxygenation Reflectometer}

Oxyhemoglobin saturation measurement is based on the differences in the absorption properties of hemoglobin in it's oxygenated vs. deoxygenated states as presented in Figure 10B. The tissue is illuminated at two wavelengths: $585 \mathrm{~nm}$ and 577 $\mathrm{nm}$. At $585 \mathrm{~nm}$, oxyhemoglobin and deoxyhemoglobin have the same absorption characteristics (the isosbestic point); thus, the light emitted from the tissue reflects changes in tissue blood volume. At $577 \mathrm{~nm}$, oxyhemoglobin has a higher absorption ability (lower reflectance) than deoxyhemoglobin; thus, at this wavelength, the emitted light intensities are affected by the oxygenation levels as well as by the changes in blood volume at the measurement site. Therefore, subtracting changes in 585 $\mathrm{nm}$ reflectance from those at $577 \mathrm{~nm}$ provides a parameter correlated to net changes in blood oxygenation $[28,76]$.

\section{NADH fluorometry}

Light from brain tissue within the probe's detection volume (approximately $0.1 \mathrm{~cm} \mathrm{3)} \mathrm{was} \mathrm{analyzed} \mathrm{by} \mathrm{a} \mathrm{four-channel}$ photometer designed for multi wavelength detection. The photometer was custom made for the investigators by the
Biomedical Instrumentation Group of the University of Pennsylvania (Fig. 10A). Excitation light source was a Nikon $100 \mathrm{~W}$ Mercury arc lamp. Wavelengths for tissue illumination and subsequent detection were determined by eight optical filters circumferentially arranged on a wheel rotating at approximately 3,000 rpm. The optical filters used had a narrow band pass with very high roll off outside the selected pass band (NB and DF series, Omega Optical, Brattleboro, VT). The four illumination/return wavelength pairs used in this study are listed in Figure 10C. A photodiode in the optical path detected fluctuations in the mercury lamp output; these fluctuations were then fed back for compensation. Channel 2 detected light at $450 \mathrm{~nm}$, the maximal intensity wavelength for NADH fluorescence emission. Factors besides the local intracellular NADH concentration that influenced the channel 2 signal, however, included changes in tissue emissivity and local reabsorption caused by changes in blood volume and blood oxygenation.

The connection between the brain and the TVMS was done by a flexible light guide inserted through the wall of the hyperbaric 
chamber. The fiber optic probe includes fibers that were connected to the two instruments as shown in the enlargement of the bundle tip. The measurement of $\mathrm{HbO}_{2}$, reflectance at $366 \mathrm{~nm}$ and NADH were performed by the same excitation and emission fibers. The CBF was measured by 3 optical fibers located in the center of the time sharing bundle of fibers. The animal was placed in a Plexiglas cage, fitted to the rat's size and was allowed to recover for about $30 \mathrm{~min}$. The normal response to anoxia was checked by the NADH increase and $\mathrm{HbO}_{2}$ decrease.

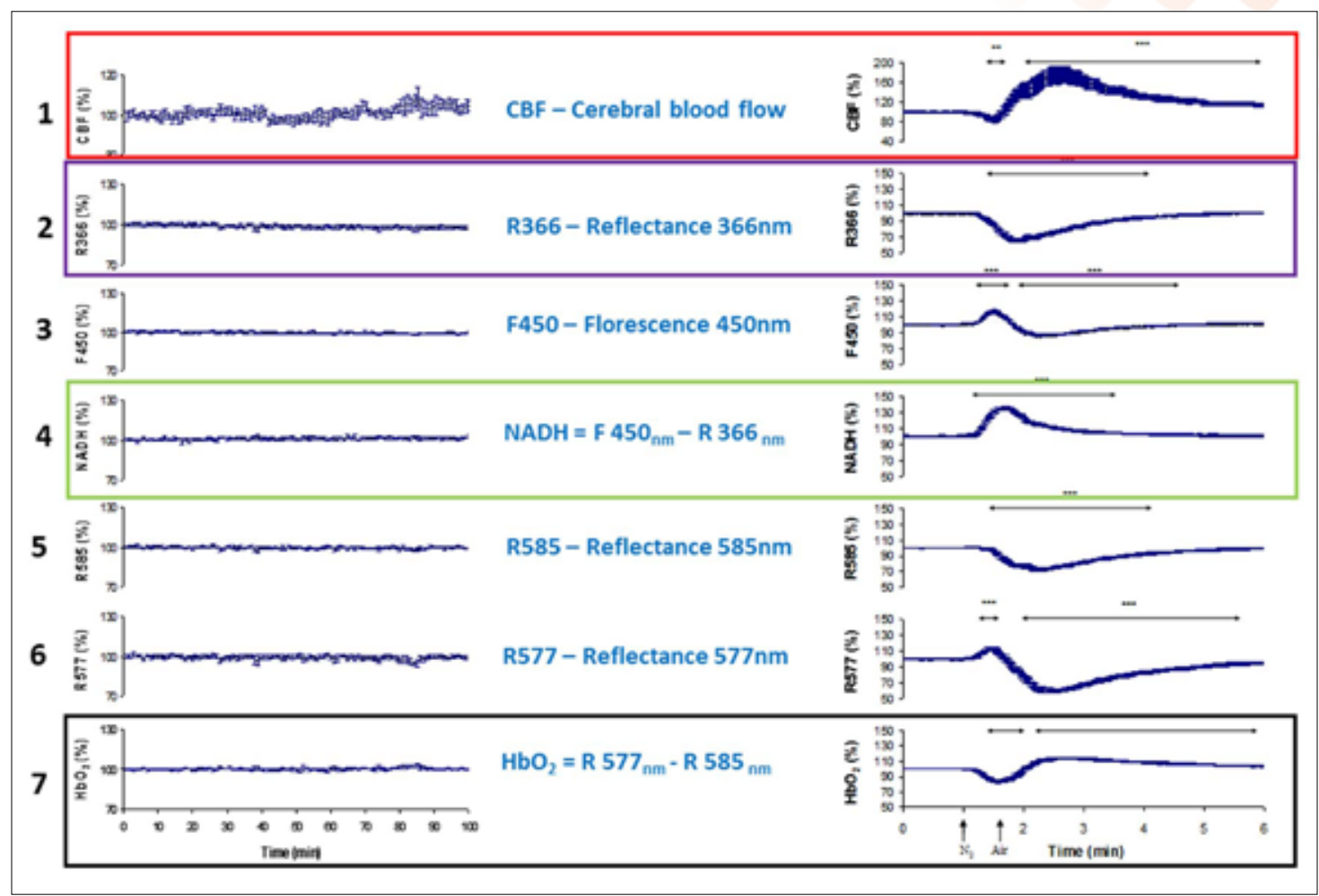

Figure 11: Recording of the measured signals and calculated parameters performed by the Tissue Vitality Monitoring System (TVMS). The left side show the 5 measured $(1,2,3,5,6)$ and the calculated 2 parameters $(4$ and 7$)$ measured in a 100 minutes' control period. The right side shows the response of the rat brain to anoxia induced be $100 \%$ nitrogen.

Figure 11 shows the signals that was measured using the Tissue Vitality Monitoring System-TVMS, and the 4 calculated physiological parameters. The $1^{\text {st }}$ parameter (red) is the output of the laser Doppler flowmeter as is. The channels 2 and 3 are measured by the fluorometer part of the TVMS but the fluorescence signal must be corrected for hemodynamic artifacts related mainly to changes in blood volume (reflectance signal in purple) at the monitored site. The corrected NADH fluorescence parameter is presented in trace 4 (green). Channels 5 and 6 are the output of the time-sharing part of the TVMS measuring the reflectance intensity in the 2 specific wavelengths. The subtraction of trace $585 \mathrm{~nm}$ from that of 577 $\mathrm{nm}$ provides the oxygenation level of the hemoglobin in the microcirculation (channel 7 in black).

The left side of Figure 11 shows the 100 minutes' control monitoring of the rat brain. In the right side, the effects of anoxia are presented. It's important to note that the response recorded in line 2 and 5 are almost identical since they are measuring the changes in blood volume occurred in the brain under anoxia. Figure 12A shows the 4 calculated responses of the rat's brain to anoxia (A) extracted from the record seen in Figure 11 (right side).

\section{Effects of normobaric $(\mathrm{NH})$ and hyperbaric $(\mathrm{HH})$ hyperoxia on brain energy metabolism}

It is well known and published that the level of oxygenated $\mathrm{HbO}_{2}$ at the microcirculation is much lower than in the systemic arterial blood (about 98\% saturation) measured by pulse oximetry. The oxygenation level of the $\mathrm{HbO}_{2}$ is dependent on the oxygen consumed by the mitochondria and the microcirculatory blood flow. The hypothesis was that hyperbaric oxygenation(HBO) may lead to maximal level in microcirculatory $\mathrm{HbO}_{2}$ due to the amount of the dissolved $\mathrm{O}_{2}$ to provide the $\mathrm{O}_{2}$ consumed by the brain, and therefore no $\mathrm{O}_{2}$ will be dissociated from the $\mathrm{HbO}_{2}$. The aims of this study were as follows:

- To determine the HBO level at which in vivo hemoglobin oxygenation in brain microcirculation, is maximal.

- To find the relation between those values to the real time mitochondrial NADH state.

After preparation of the rats as described previously the rat (in the Plexiglas cage) was placed in a 150-1 hyperbaric chamber, containing a special cage heated by water (Bethlehem Corp. FM-21-A) [75]. Four hours after anesthesia, the rats were observed in a fully awake state and the experiment started. The chamber was flushed with $100 \%$ oxygen, normobaric 
hyperoxia (NH) for 15 min at atmospheric pressure (cleaning phase) in order to prevent acid base disturbances and physiological $\mathrm{CO}_{2}$ elevation in the blood.

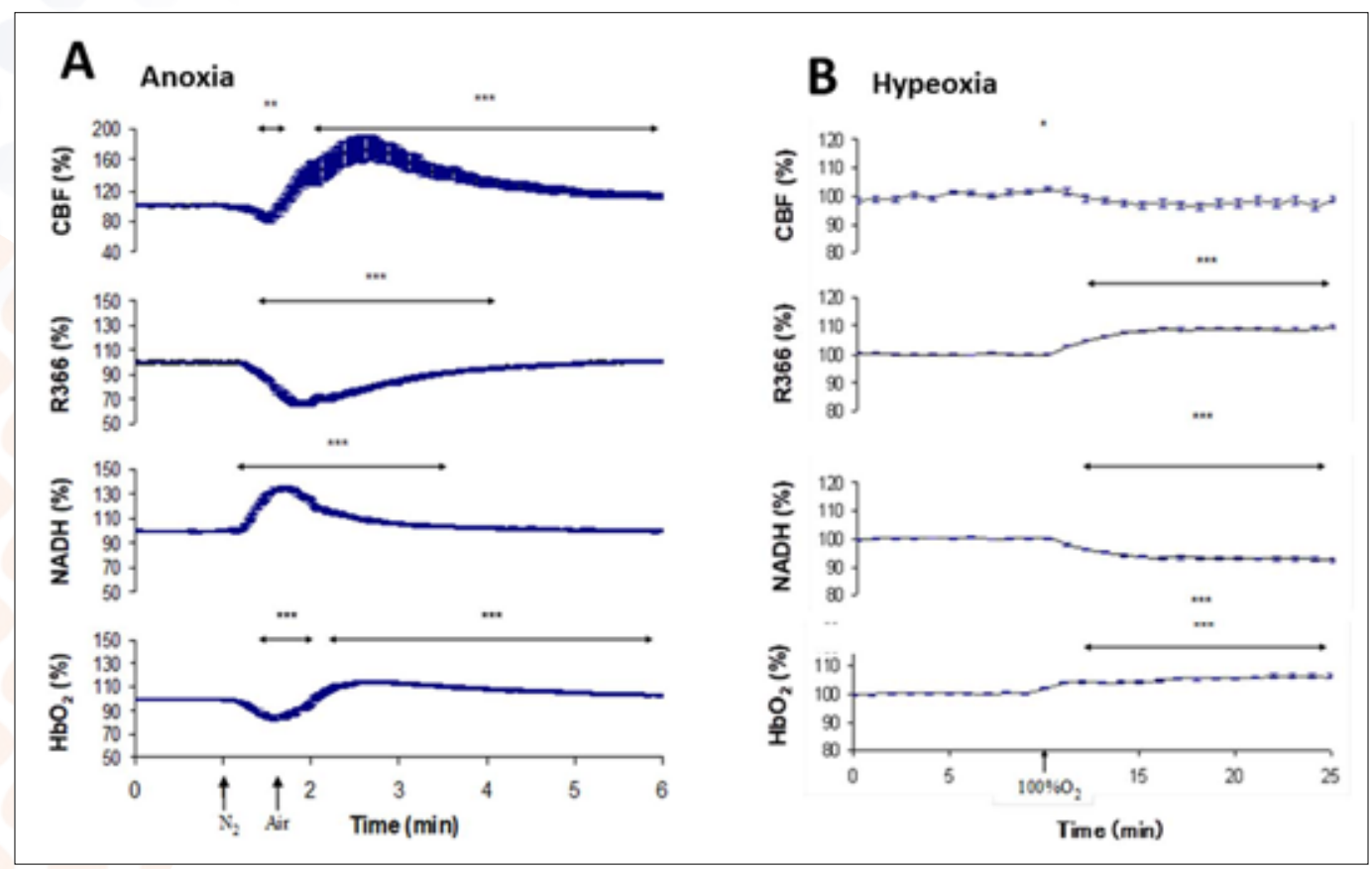

Figure 12: A - The effect of anoxia $\left(100 \% \mathrm{~N}_{2}\right)$ on cerebral blood flow (CBF), reflectance (R366), mitochondrial NADH redox state $(\mathrm{NADH})$ and hemoglobin oxygen saturation $\left(\mathrm{HbO}_{2}\right)$ in the normal brain. Values are shown as mean percent values $\pm \mathrm{SE}$. $* * \mathrm{p}<0.01,{ }^{* * *} \mathrm{p}<0.001$ range of time showing significant differences found by ANOVA repeated measures. B - The effect of normobaric hyperoxia $\left(100 \% \mathrm{O}_{2}\right)$ on the 4 parameters monitored inside the hyperbaric chamber. The results are the average of 28 rats exposed to the hyperoxia. The ${ }^{* * *}$ represents the significant level of $\mathrm{p}<0.001$.

Figure 12B shows the effect of normobaric hyperoxia (NH) recorded in 28 rats for 25 minutes on the various parameters. The NH was induced by exposing the rat located in a hyperbaric chamber to $100 \%$ oxygen in 1 atmosphere [75].

The small decrease in CBF was not significant during the entire recording. The large significant increase in the reflectance signal $(\mathrm{R} 366 \mathrm{~nm})$ may suggest a decrease in blood volume and the same results were obtained in the $585 \mathrm{~nm}$ reflectance (not shown in the record). The NADH levels decreased (oxidized) significantly during the entire exposure to $100 \%$ oxygen and it was correlated to the increase in the microcirculatory $\mathrm{HbO}_{2}$ oxygenation (increased signal).

One group of rats was tested to show the effect of hyperbaric hyperoxia $(\mathrm{HH})$ at various pressure levels $(1.5,2,2.5,3$ and 3.5 ATA) on the measured parameters (Fig. 13A)

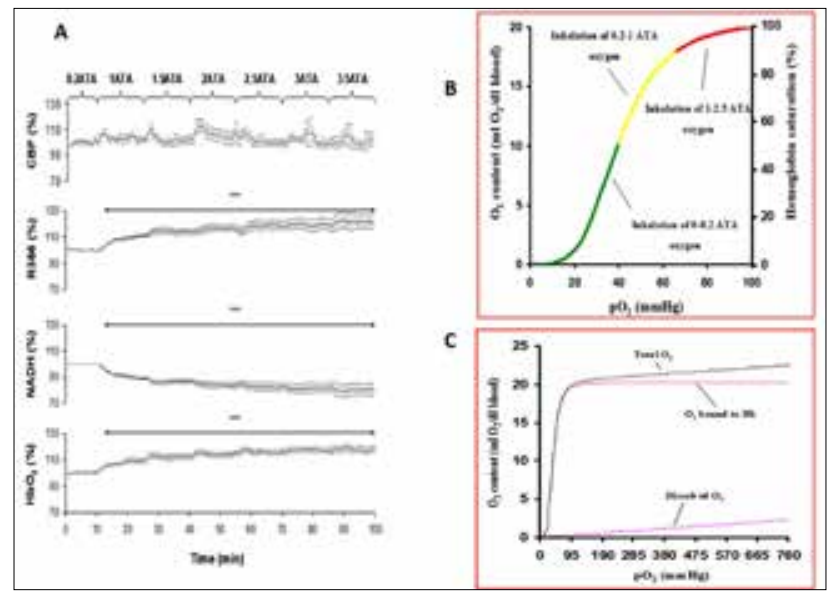

Figure 13: A - The effect of normobaric hyperoxia $\left(100 \% \mathrm{O}_{2}\right)$ and various levels of hyperbaric hyperoxia (1.5 ATA, 2.0 ATA, 2.5 ATA, 3 ATA and 3.5 ATA) on cerebral blood flow (CBF), reflectance (R366), mitochondrial NADH redox state and hemoglobin oxygen saturation $\left(\mathrm{HbO}_{2}\right)$. The data are presented as mean percent values $\pm \mathrm{SE}$. B - Hemoglobin oxygen saturation curve in the microcirculation. The green sector represents the saturation of the $\mathrm{Hb}$ in the tissue when the animal breath air $\left(0.2\right.$ ATA $\left.\mathrm{O}_{2}\right)$. The yellow section represents the saturation level when breathing up to 1 ATA $\mathrm{O}_{2}$. The red line covers the range of breathing 1-2.5 ATA O. 
$\mathrm{C}$ - Saturation curve of $\mathrm{Hb}$ measured in the lung while breathing up to $1 \mathrm{ATAO}_{2}(760 \mathrm{mmHg})$. The red line represents the oxygen bound to hemoglobin, the purple line the dissolved $\mathrm{O}_{2}$ and the black line shows the total amount of oxygen transported by the blood.

Since the range of therapeutic HBO pressure levels confirmed by the Undersea and Hyperbaric Medical Society (UHMS) for various pathological conditions was between 2 and 3 ATA we decided to test the effect of these pressures, compared to the control group at 0.2 ATA, on the measured parameters. The experiments started from normal pressure (0.2 ATA) for 15 min. Then, pressure was elevated gradually starting from $(\mathrm{NH})$ at 1 ATA and continued to hyperbaric pressure elevating by increments of 0.5 ATA from 1.5 to 3.5 ATA, after washing the chamber with $100 \% \mathrm{O}_{2}$. Each step of pressure continued for $15 \mathrm{~min}, \mathrm{HbO}_{2}$ increased significantly $(\mathrm{p}<0.001)$ and $\mathrm{NADH}$ redox state decreased significantly $(\mathrm{p}<0.001)$. The $366 \mathrm{~nm}$ reflectance augmented significantly $(\mathrm{p}=0.001)$ showing a decrease in blood volume, whereas CBF did not demonstrate significant changes. In addition, Bonferroni post hoc tests showed significant differences (between $\mathrm{p}<0.05$ to $\mathrm{p}<0.001$ ) between the control values at 0.2 ATA (at 5 min of recording) and almost all other time points $(20,35,50,65,80$ and $95 \mathrm{~min})$, where the parameters reached steady state for each level of pressure induced. These results show that the gradual increases in hyperbaric pressures were significantly different compared to normoxia (0.2 ATA) in reflectance, NADH redox state and $\mathrm{HbO}_{2}$. Significant differences $(\mathrm{p}<0.001)$ were also found between the control and experimental groups at the same 6 time points (from 20 to $95 \mathrm{~min}$ ) showing a significant effect of $100 \% \mathrm{O}_{2}$ and the various levels of hyperbaric pressure.

This study examines the relationship between intracellular mitochondrial NADH redox state, microcirculatory blood flow, tissue reflectance and hemoglobin oxygenation under normoxia $\left(21 \% \mathrm{O}_{2}\right)$, normobaric hyperoxia $\left(100 \% \mathrm{O}_{2}\right)$ and variable levels of hyperbaric hyperoxia. Parallel to the decrease in blood volume (increased reflectance), we observed an oxidation of brain NADH (Fig. 13A), suggesting that NADH is not fully oxidized in the normoxic brain in vivo and can be oxidized even further under hyperbaric hyperoxia conditions. Questions arise to how much of this oxygen is actually bound to hemoglobin; how much oxygen is dissolved in the plasma of the circulating blood; and how the relationship between the two $\mathrm{O}_{2}$ carrying mechanisms is affected by hyperbaric oxygenation. We found that the hemoglobin saturation in the brain tissue increases by an asymptotic curve as the chamber pressure rises, approximating a plateau at about 2.5 ATA (Fig. 13A). This may imply that tissue $\mathrm{HbO}_{2}$ is near the maximal value at 2.5 ATA, and pressures above 2.5 ATA do not significantly alter the tissue hemoglobin saturation. The significant increase in $\mathrm{HbO}_{2}$, resulting from increased oxygen partial pressure, evidences that brain microcirculatory hemoglobin was not fully oxygenated under normal conditions and it reached a maximal saturation at 2.5 ATA when all $\mathrm{O}_{2}$ supply to the cells was provided by the $\mathrm{O}_{2}$ dissolved in the plasma. Elevation of the pressure above 2.5 ATA did not further oxygenate the hemoglobin and no changes were found in $\mathrm{HbO}_{2}$ levels. Our work shows that most of the oxidation of $\mathrm{NADH}$ and the oxygenation of $\mathrm{HbO}_{2}$ take place in the proximity of 2.5 - 3 ATA.

In our previous review paper we used mathematical modeling to calculate the level of saturation of hemoglobin in the brain in vivo [75]. We came to the conclusion that under normoxic conditions ( 0.2 ATA) the Hb saturation, in the brain, is $45 \%$, under 1ATA the saturation is about $85 \%$ and at 2.5 ATA the saturation is $95 \%$. Figure $13 \mathrm{C}$ show (schematically) the changes in hemoglobin saturation in the microcirculation due to increase in the pressure of oxygen in the hyperbaric chamber. It's important to note that the $\mathrm{Hb}$ Saturation of $45 \%$ in the brain microcirculation (green line) is due to the high oxygen consumption rate by the brain mitochondria that was downloaded from the highly saturated hemoglobin. Increasing the level to 1ATA in the chamber will add another $35 \%-40 \%$ to the saturation of $\mathrm{Hb}$ in the microcirculation. Additional final elevation of the oxygen pressure to 2.5ATA will add to the $\mathrm{Hb}$ another $10 \%$ of saturated $\mathrm{Hb}$. Any further elevation in the chamber pressure will not affect the $\mathrm{Hb}$ saturation which is at its maximal value around $100 \%$ saturation. From this point, the supply of oxygen to the brain will be provided by the dissolved oxygen in the plasma which was elevated by the increased pressure in the chamber and not from the fully oxygenated hemoglobin. Figure 13D show the effect of oxygen level in the chamber up to 1ATA $(760 \mathrm{mmHg})$ on the oxygen content bound to the hemoglobin in comparison to the dissolved oxygen in the plasma (purple lines). The elevation of the total oxygen content (black line), is due to the increased capacity of $\mathrm{O}_{2}$ in the plasma and not the $\mathrm{O}_{2}$ bound to $\mathrm{Hb}$.

\section{Monitoring and calculation of tissue metabolic score}

As seen in Figure 1, there was a need to calculate and present the balance between oxygen supply and demand in a specific organ such as the brain or the urethra of patients. In order to calculate a useful score, it is necessary to monitor and use as many parameters as possible representing the two side of the equation of oxygen balance. We decided to use up to 4 parameters in the monitoring device that will provide the real time trends of the parameters and the calculated tissue metabolic score (TMS). The need for new approaches in evaluating the clinical status of patients is very wide. For example, the interpretation of the physiological status of anesthetized patients in the OR is very subjective and therefore may be evaluated differentially by various anesthesiologists. The same problem is demonstrated in patients hospitalized in the various intensive care units that need additional monitoring approaches to evaluate objectively their condition. As of today, there is a discrepancy between the large amount of data collected by various techniques and the ability to integrate it into a practical objective tool to be used in clinical practice. Our effort to apply our developed multiparametric system to clinical daily use, required the development of a new indexing technique for data interpretation. After the accumulation of huge amount of experimental animal's results, we decided to develop a preliminary tool named Tissue Metabolic Score (TMS). In the present study we are presenting the preliminary developed TMS that could be used in evaluating the metabolic status of the monitored tissue in real time. We used the brain 
as a typical organ for the calculation of the (brain metabolic score) BMS, but the same approach could be used for other organs or tissues. The ultimate goal of our study is to develop the Tissue Metabolic Score (TMS) for tissues that could be monitored in the intensive care units or in the operating rooms. In order to develop the BMS/TMS we used the multiparametric monitoring system described in details and the development of the BMS/TMS appeared in our publication [77]. The device is seen in Figure 14B and the details appeared in our paper
$[78,79]$. The nature of the 4 measured parameters presented in Figure 14A1-A4 are NADH redox state, tissue blood flow, hemoglobin oxygenation and tissue reflectance. The connection of the monitored tissue to the device is done by a fiber optic probe that is specific to the tissue/organ monitored. Figure 14C shows the display of the device shows in real time the levels of the monitored parameters that could be calculated to provide the TMS/BMS seen in part D of the figure.

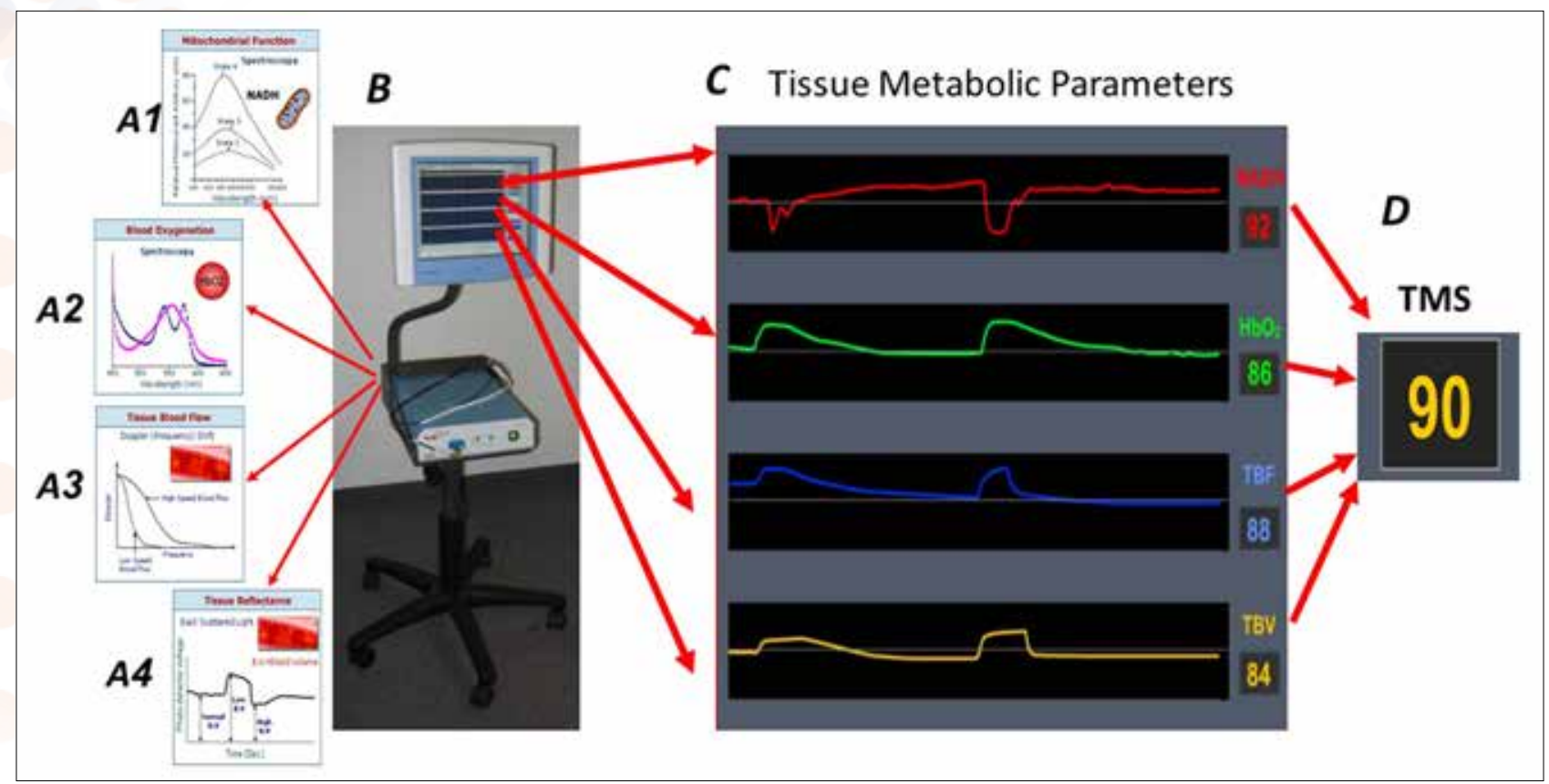

Figure 14: The developed medical device (B) enabling the monitoring of mitochondrial and tissue functions in vivo. $A_{1}-A_{4}$, the 4 parameters monitored simultaneously. The display of the four monitored parameters and the calculated Tissue Metabolic Score are seen in the right side.

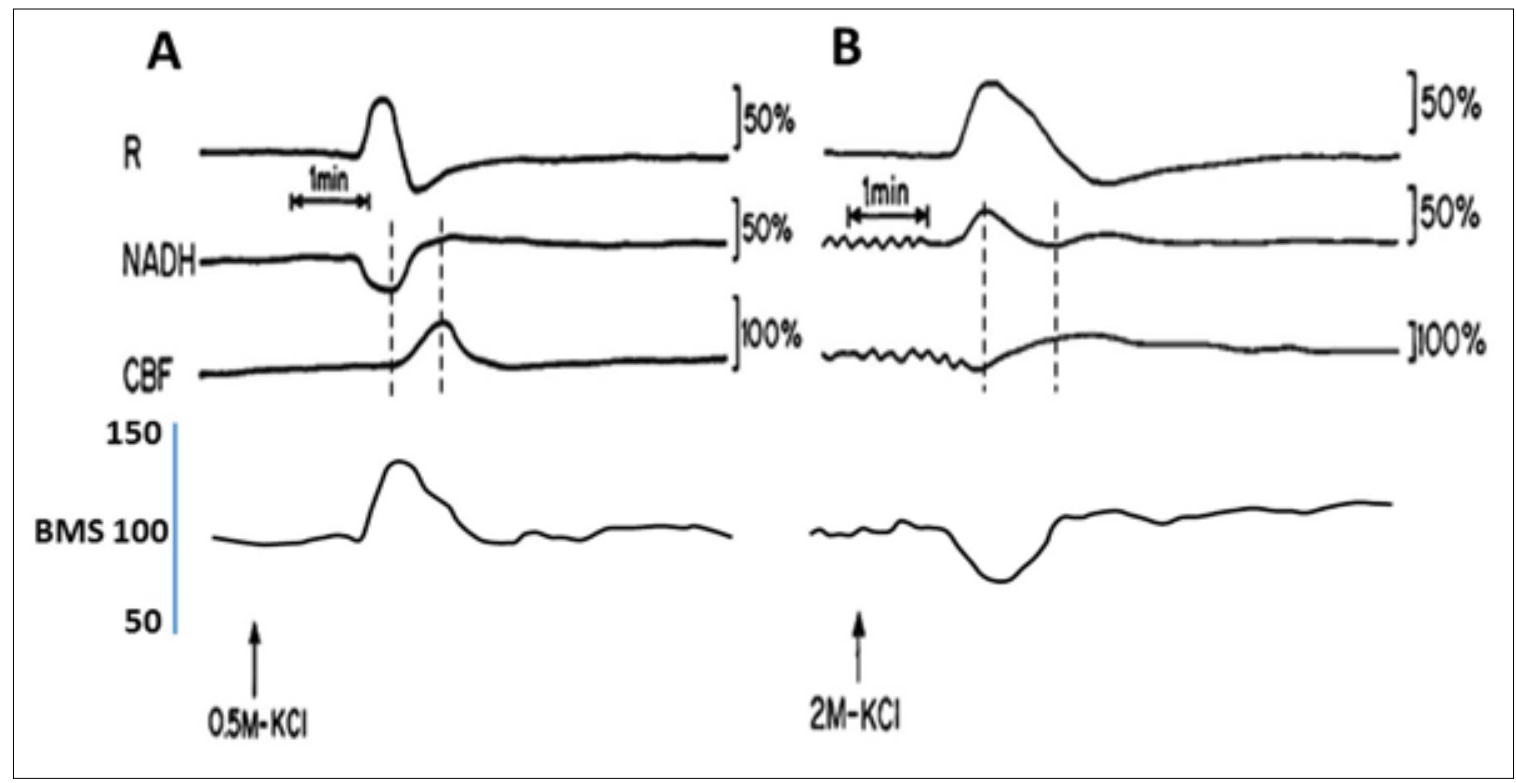

Figure 15: Responses of the normoxic (A) and partial ischemic or hypoxic (B) rat brain to cortical spreading depression induced by applying $\mathrm{KCl}$ solution to the cerebral cortex. BMS-Brain Metabolic Score. 
Figure 15 is an analog tracing that illustrates the effect of Cortical Spreading Depression- CSD on the brain cortex during normoxia (A) and hypoxia (B) of the same animal. CSD during normoxia (A) caused a biphasic response in reflectance, an increase that was followed by a decrease. Mitochondrial NADH decreased showing an oxidation cycle and CBF increased. During hypoxia (B), the increase in reflectance augmented and the decrease phase reduced. NADH and CBF under hypoxic conditions changed their responses to CSD: in NADH an initial reduction cycle that was followed by a small oxidation one; CBF declined parallel to the increase in NADH and later on, a small increase was seen, which was accompanied by the small oxidation cycle in NADH. In addition, CSD wave duration prolonged during hypoxia as compared to normoxia. It was found that the responses to cortical spreading depression (CSD) in normoxic and ischemic brain are different [80]. Rosenthal \& Martel showed that ischemia affected the response to CSD, namely, instead of NADH oxidation, an increase in NADH was recorded [81].

More than 20 years ago we reported, for the first time, on the development of CSD in the brain of a comatose patient [82]. In this patient, the typical "oxidation cycle" of NADH was replaced by a "reduction cycle" due to a decrease in $\mathrm{O}_{2}$ compensation capabilities when the patient show signs of brain deterioration due to high intracranial pressure (ICP) levels.

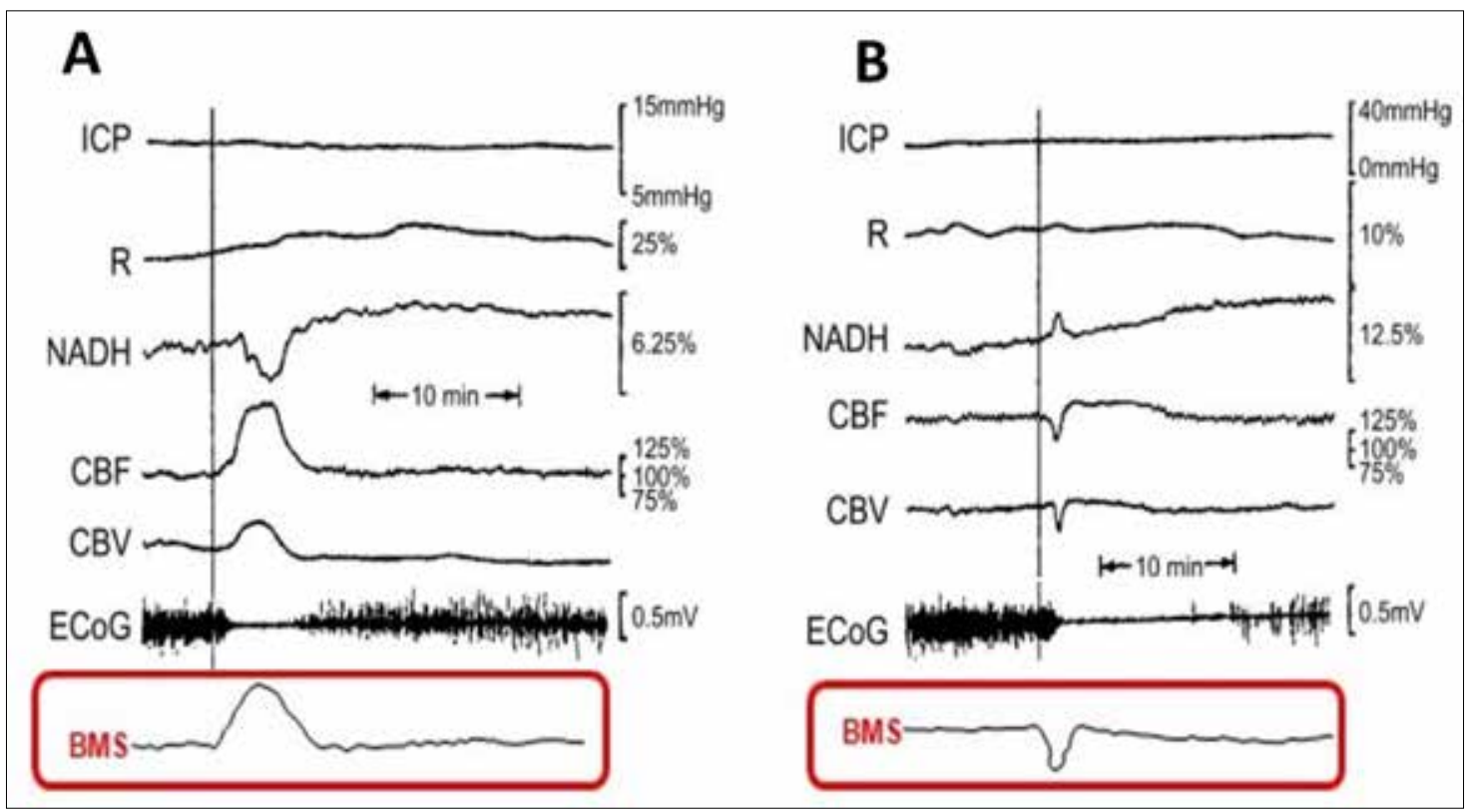

Figure 16: Two events developed in a head injured patient in the neurosurgical ICU. Brain Metabolic Score (BMS) calculated from the following parameters CBF - Cerebral Blood Flow, R Reflectance, NADH - mitochondrial NADH redox state

Figure 16 presents the responses to SD in patients. In patients' monitoring, we want to use the NADH trace as an indicator to the physiopathological state of the patient or the brain in this example. As seen, the two responses developed in the neurosurgical patients (A and B) are not the same. Therefore, we concluded that the brain of the patient in state $\mathrm{A}$ was probably normoxic while in $\mathrm{B}$ the brain was partially ischemic. Indeed, this patient was deteriorating in time and finally brain death was determined [82].

This example demonstrates that the basic pathophysiological events developed in patients present very similar results as compared to those monitored in animal models. The calculated BMS traces, measured from the patient shown in part A and B are presented in the lower and the difference in the responses to CSD is very obvious. The initial response measured in the patient (Fig.16 part A) is very similar to the responses measured in rat shown in part $A$ and in Figure 15. The same similarity is seen in the TMS responses shown in part B in Figure 16 and part B in Figure 15.

\section{Possible monitoring of COVID-19 patients in the ICU and critical care units}

Monitoring of patients in the ICU is much more complicated due to the systemic events occurred in the patient such as Sepsis or the development of Acute Respiratory Distress Syndrome (ARDS). The physiological mechanism behind the monitoring approach of those patients are described in Figure $17 \mathrm{~A}+\mathrm{B}$. The pattern of pathophysiological cascade of events that may occur in many emergency clinical situations in adult patients and may lead to morbidity and mortality. As shown, the pathophysiology developed in a COVID-19 patient may lead to metabolic disturbances and may end up in cellular energy derangement. Under this situation the metabolic state of the body will be deteriorated (BEMS) and energy failure will develop due to ARDS. As a central protection mechanism, blood flow redistribution will occur and the three protected organs shown in Figure 17A (brain, heart and adrenal gland) will receive more blood and $\mathrm{O}_{2}$, while the peripheral organs (Fig. 17B) or areas (skin and muscles), as well as others less vital visceral organs, will undergo vasoconstriction and a decrease in blood flow and $\mathrm{O}_{2}$ supply will occur. Monitoring at the cellular function is the most significant indicator of the 
metabolic state of patients in critical care medicine.

The energy balance in the most vital organs (part A) will remain positive due to higher blood flow while the less vital organs (part B) will be hypo perfused and a negative energy balance will have developed.

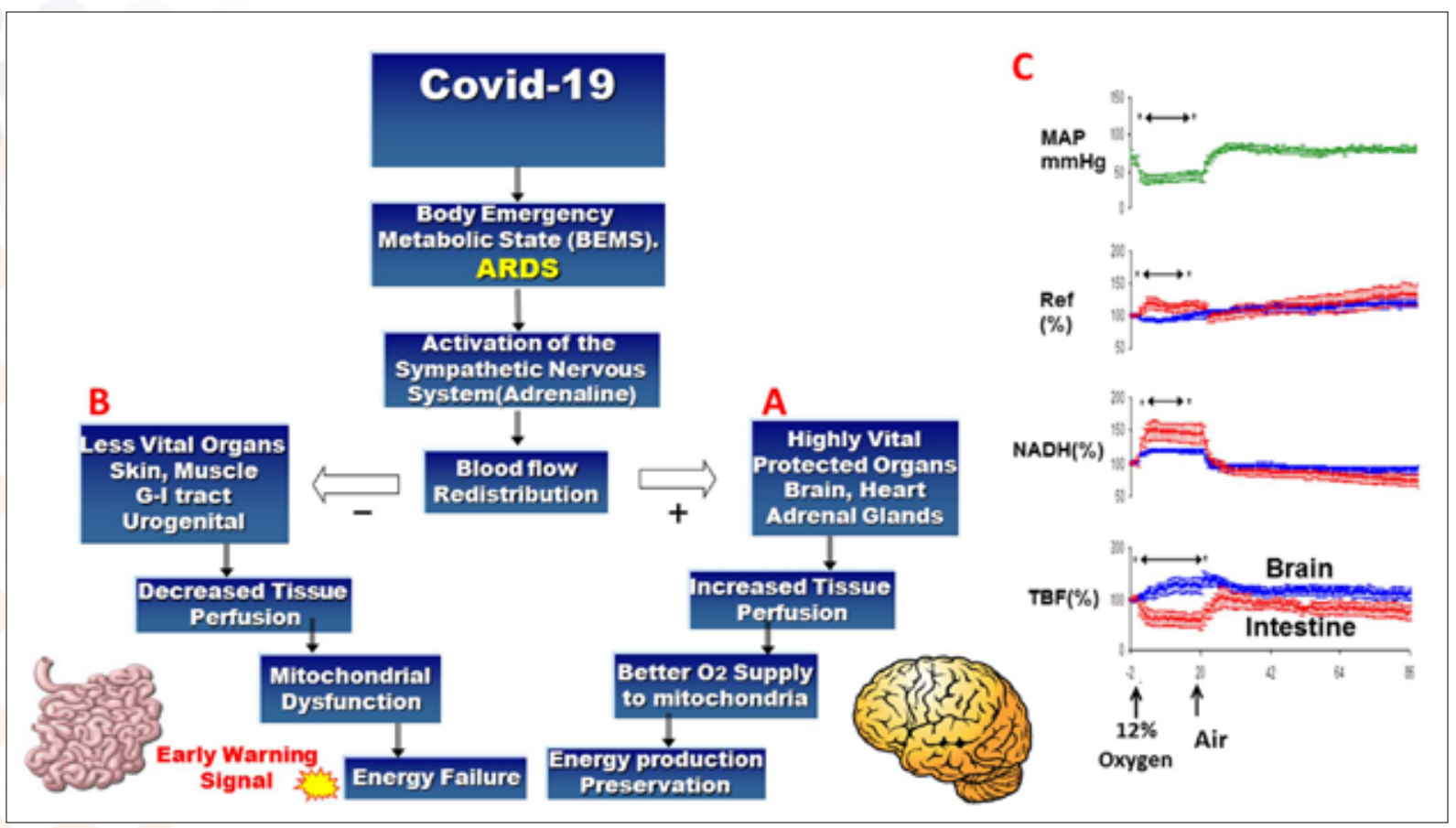

Figure 17: Left side - Schematic presentation pathological state developed in Covid-19 patients that may lead to the development of body emergency metabolic state (BEMS). As a result, blood flow redistribution may lead to an increase in blood flow to the most vital organs (A) and a decrease in blood flow to the less vital organ (B). C - A typical experiment in which hypoxia (12\% oxygen) was induced in a rat. The two organs monitored were: Brain. And small intestine. The parameters shown include: Mean

Arterial Pressure (MAP), Tissue Blood Flow (TBF), reflectance (Ref) and corrected fluorescence (NADH).

As presented in Figure 17 (left side), the blood flow redistribution mechanism will affect the energy production by the mitochondria in the most vital and less vital organs in the body. This change in mitochondrial function will affect the production of ATP. This change occurred in the less vital organs could serve as an early warning signal to the changes developed in oxygen balance in the patient's body. In order to ensure reliable monitoring of two organs simultaneously using the (Multi Site Multi Parametric) MSMP device, we run control experiments in which monitoring of the brain and small intestine was preformed following exposure of the animal to systemic hypoxia. This system monitors both NADH redox state using the Fluorometry technique and Tissue Blood Flow (TBF) using the Laser Doppler Flowmetry (LDF) simultaneously and from the same location on each organ.

Figure $17 \mathrm{C}$ shows the effects of hypoxia $\left(12 \% \mathrm{O}_{2}\right)$ on the brain and intestinal metabolism [83]. The following results were recorded, MAP decreased by $34 \pm 4 \mathrm{mmHg}$ immediately after the rats started breathing the low-oxygen mixture. This change was followed by a decrease in TBF in the intestine to a level of $56 \pm 13 \%$ and a tendency of CBF increase to a level of $140 \pm 12 \%$. Simultaneously, the reflectance in the intestine increased (119 $\pm 8 \%$ ), while in the brain it decreased $(92 \pm 2 \%)$. The changes in the blood supply to the organs produced corresponding changes in the levels of mitochondrial NADH. In the intestine, $\mathrm{NADH}$ increased to a level of $151 \pm 14 \%$ and remained at this level throughout the entire hypoxic period, while in the brain NADH reached a level of $119 \pm 2.8 \%$ When the rats started breathing air, all the parameters returned to the basal level within $2 \mathrm{~min}$ in the intestine, whereas in the brain hyperemia was observed for 11 minutes, followed by full recovery. With reference to NADH and reflectance, full recovery was observed immediately after the rats started breathing air.

The results of the present study show high correlation between tissue blood flow $\left(\mathrm{O}_{2}\right.$ supply) monitored by the LDF technique and the energetic state of the small intestine (mitochondrial NADH redox state). However, in the brain although TBF increased, NADH also increased.

The utility of the calculated tissue metabolic score (TMS) is presented in Figure 18. In the rat used in the study, the brain and small intestine were monitored under the injection of two levels of norepinephrine (NE). The effect of the NE led to a clear increase in blood pressure depending of the dose injected. The responses of the 3 parameters measured in the two organs were in the opposite directions. In the brain (Fig. 18A), the clear increase in $\mathrm{CBF}$ and $\mathrm{CBV}$ was correlated to the oxidation of NADH redox state. In the small intestine (Fig. 18B) the NE led to opposite responses compared to the brain. The tissue metabolic score that was calculated, as seen in the lower records (TMS), shows clearly that the less vital organ is clearly J B \& Bio Engine; $2020 \quad$ www.unisciencepub.com Volume $1 \mid$ Issue 3 
exposed to ischemia, while the brain is preserved and well oxygenated under the NE injection.

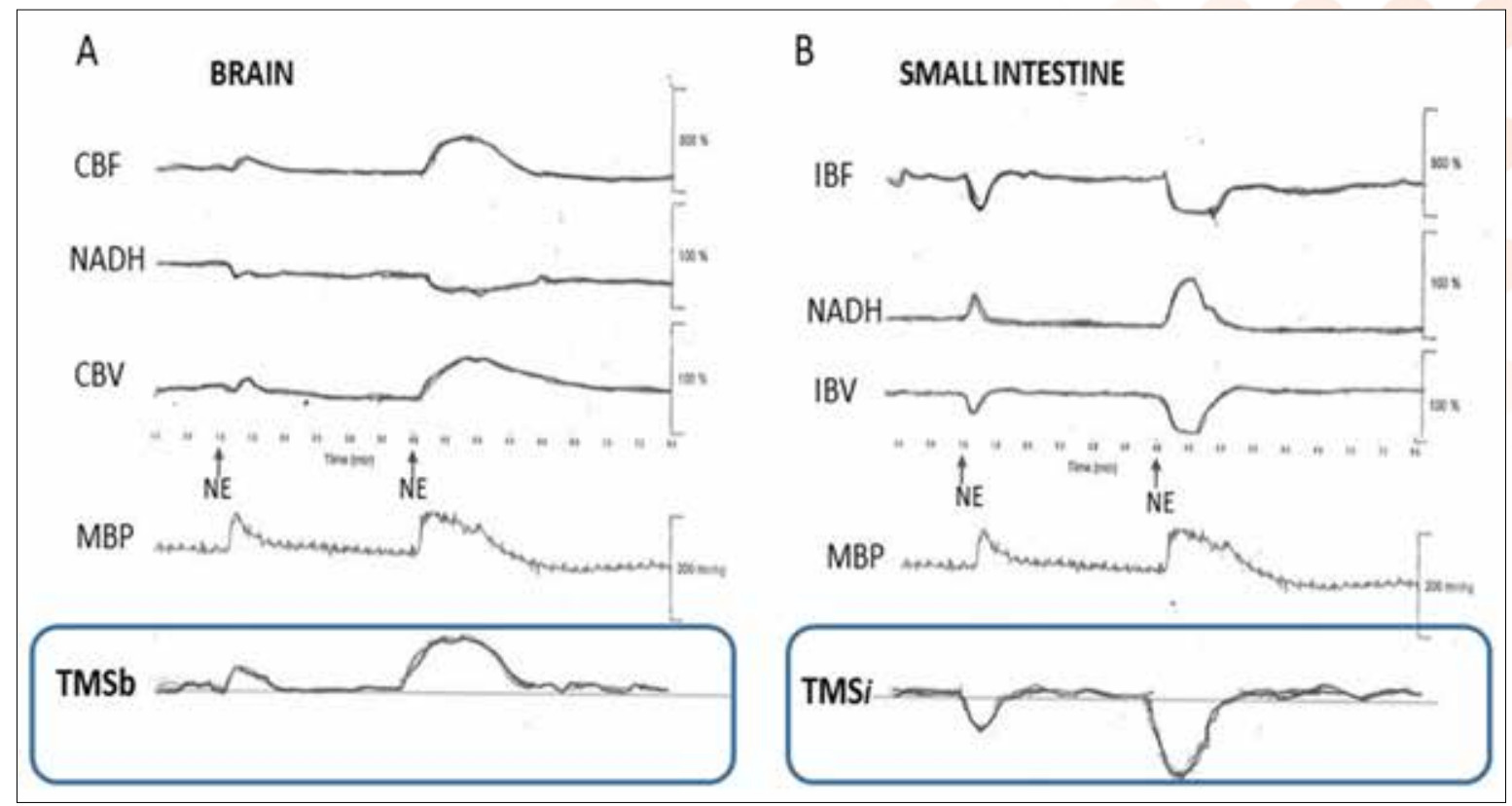

Figure 18: The responses of the Brain (A) and small intestine (B) to two levels of norepinephrine injected to the anesthetized rat. $\mathrm{CBF}$ and $\mathrm{CBV}$ - Cerebral blood flow and volume measured by a laser Doppler flowmeter, MBP - Mean blood pressure, IBF and IBV - Intestinal blood flow and volume, TMSb and TMSi - Tissue Metabolic Score calculated for the brain and small intestine.

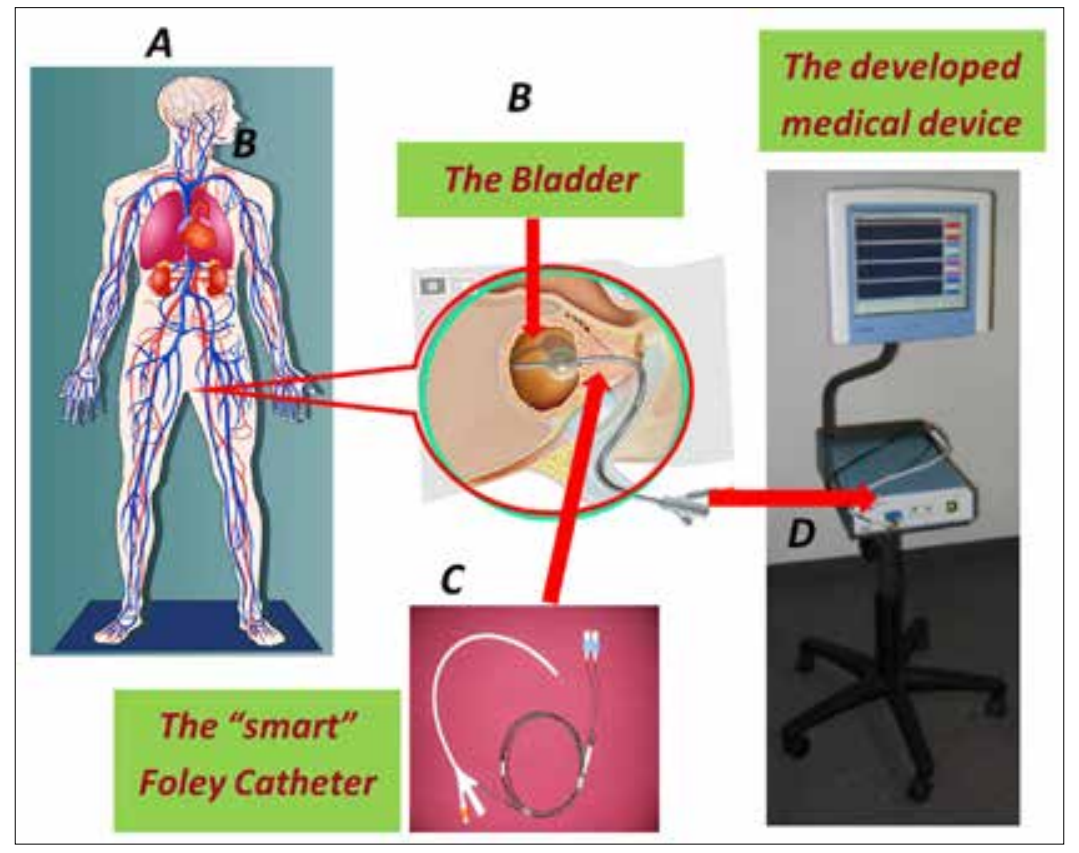

Figure 19: The new medical device developed for the monitoring of patients in critical care medicine (right side). The 3-way Foley catheter inserted to the patient's urethra for the measurement of tissue oxygen balance.

Figure 19A and B shows the location of the monitoring site suggested for the COVID-19 patients, namely the urethra and the urinary bladder. The "smart" Foley catheter seen in part C of the figure includes a bundle of optical fibers in the wall. The 3-way Foley catheter is connected to the device at point D.

The shift from a single parameter to multiparameter monitoring device allow us to understand the mechanism of a pathological state in more details. The use of other physiological parameters in addition to NADH redox state enabled us to understand better the mechanism behind the development of pathophysiological states in various animal models used. This approach enables a clinician to diagnose better the development of pathological states in patients. Ekbal et al, described the technology available 
to monitor tissue level perfusion, oxygenation and metabolism in critical care patients [84]. Dyson and Singer suggested that monitoring of tissue oxygen tension may be useful for clinical use but further validation is needed [85].

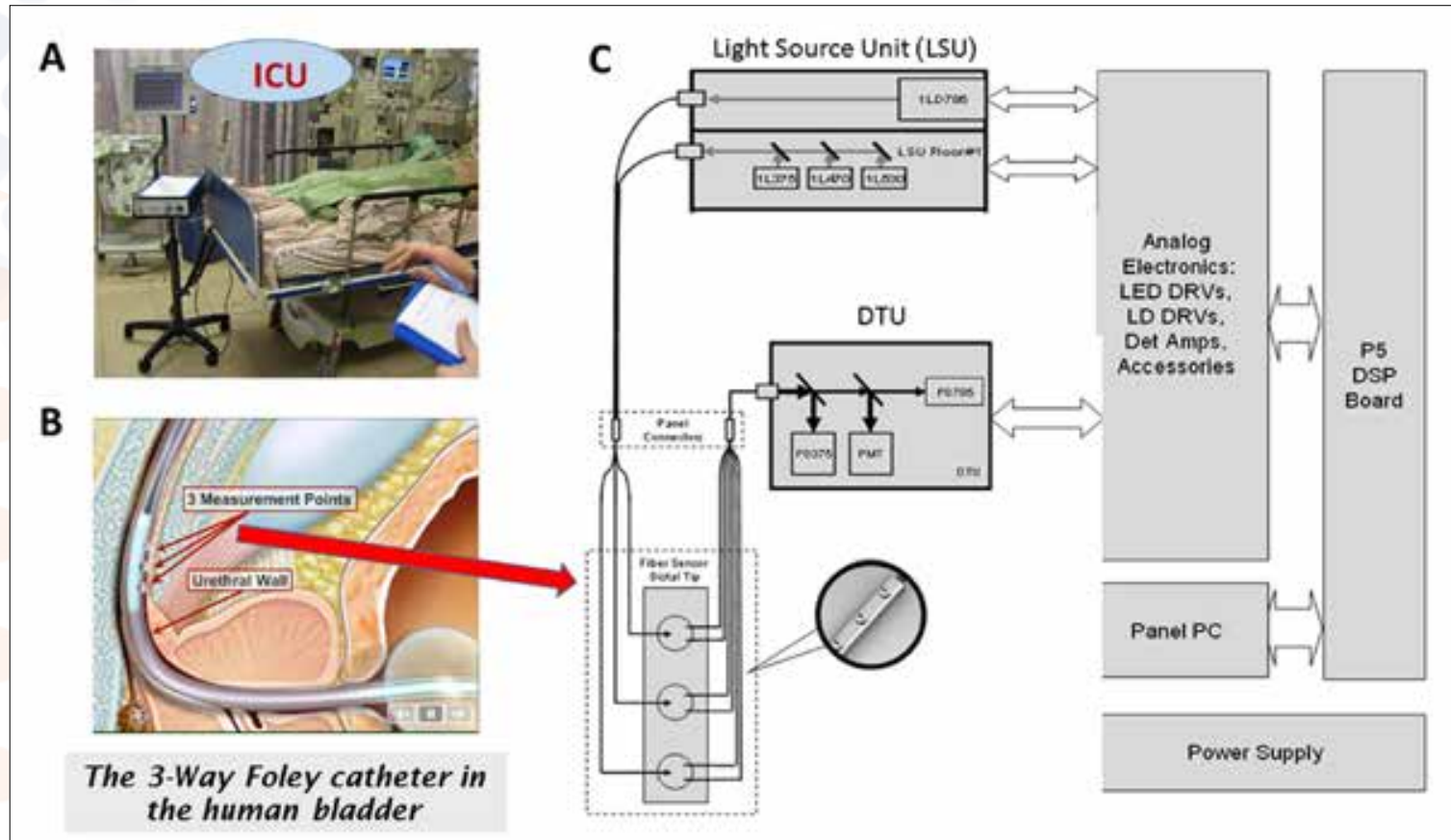

Figure 20: A - The medical device developed for the monitoring of mitochondrial and microcirculatory functions from tissues in vivo. The device seen is connected to a patient via a Urethral Foley catheter. B - The location of the 3-way Foley catheter and the three monitoring sites in the urethral wall. C - The general parts of the developed medical device are presented. Schematic description of one of the floors of the medical device containing the light source unit (LSU) and the detection unit (DTU) is seen.

The attachment of the developed medical device to the patient's bed in ICU is seen in Figure 20A. The Foley catheter is located in the urethra and the three monitoring sites can be seen in part B. The main parts of the developed medical device are presented in Figure 20C including the Light Source Unit (LSU), the Detection Unit (DTU), the data acquisition and the display parts.

\section{Testing the new medical device (NMD) in animal models} Male rats (250-300 gr) and Mongolian Gerbils (50-75 gr) were used. The animals were anesthetized by Equithesin (Eth $=$ Chloral hydrate $42.51 \mathrm{mg}$; Magnesium sulfate 21.25 mg; Alcohol 11.5\%; Propylene glycol 44.34\%; Pentobarbital $9.72 \mathrm{mg}$ ) IP (intraperitoneal) injection of $0.3 \mathrm{ml} / 100$-gram body weight. The animals were kept anesthetized during the operation and during the entire monitoring period, by additional IP injections of E-th $0.03 \mathrm{ml}$ in gerbils and $0.1 \mathrm{ml}$ in rats, every 30 minutes. The addition of small volumes of E-th every 30 minutes kept the animals in a stable state. In the Gerbils, the two common carotid arteries were isolated just before brain surgery and ligatures of 4-0 silk thread were placed around them. The animal was placed in a head holder in the supine position. After a midline incision of the skin, an appropriate hole was drilled in the parietal bone of the right hemisphere. The dura mater remained intact and a light guide holder-cannula was placed in the drilled hole and extra pressure on the tissue was avoided. Two stainless steel screws in the left parietal bone were used to fix the cannula, with dental acrylic cement. Body temperature was measured by a rectal probe (YSI) and was regulated to be at the range of $35-37^{\circ} \mathrm{C}$ using a heating blanket.
Metabolic Perturbations- Ischemia: Reversible occlusion $(30 \mathrm{sec})$ of $1-2$ common carotid arteries by constricting them with threads.

Metabolic Perturbations- Anoxia: Exposure of the animal to oxygen deficient atmosphere by spontaneous breathing of $100 \% \mathrm{~N}_{2}$, for a period of time (approx. $25 \mathrm{sec}$ ) until changes are observed on the monitor, and the animal has stopped breathing. The animal is then allowed to breathe normal room air by spontaneous breathing or by short artificial respiration. Cortical Spreading depression (CSD): In this perturbation we used the same method as described in Figure 9.

Figure 21A presents the responses of the brain to ischemia (left) and anoxia (right) measured by the NMD. Actually, the NMD calculates data on 5 measured signals that are translated into the 4 physiological parameters, namely: TBF, $\mathrm{R}_{375}, \mathrm{NADH}$ and $\mathrm{HbO}_{2}$. The raw fluorescence signal is translated into the net NADH signal by subtracting the $\mathrm{R}_{375}$ from the Flu signal (not shown). The $\mathrm{HbO}_{2}$ signal is obtained by subtracting the $\mathrm{R}_{530}$ (isosbestic reflectance) from the $\mathrm{R}_{470}$ (the non-isosbestic reflectance) that are not in the figure. The net reflectance change between the $R_{470}$ and $R_{530}$ is reversed in its polarity in order to demonstrate the $\mathrm{HbO}_{2}$ in values of increase or decrease in $\mathrm{HbO}_{2}$ and not the reflectance change. As seen in Figure $21 \mathrm{~A}$, the responses to partial and complete ischemia induced by unilateral and bilateral occlusion of the carotid arteries are shown in the left side of the figure. Due to the decrease in blood flow and volume to the brain (TBF signal) all measured signals are increasing. The net changes are a large decrease in 
$\mathrm{HbO}_{2}$ correlated very well to the NADH. A small hyperemia was noticed in the TBF and $\mathrm{HbO}_{2}$ traces after the reperfusion of blood to the brain. The time needed for recovery to the base line value is much shorter in the NADH signal as compared to the $\mathrm{TBF}$ and other reflectance signals $\left(\mathrm{R}_{375}, \mathrm{R} 470, \mathrm{R}_{530}\right)$.

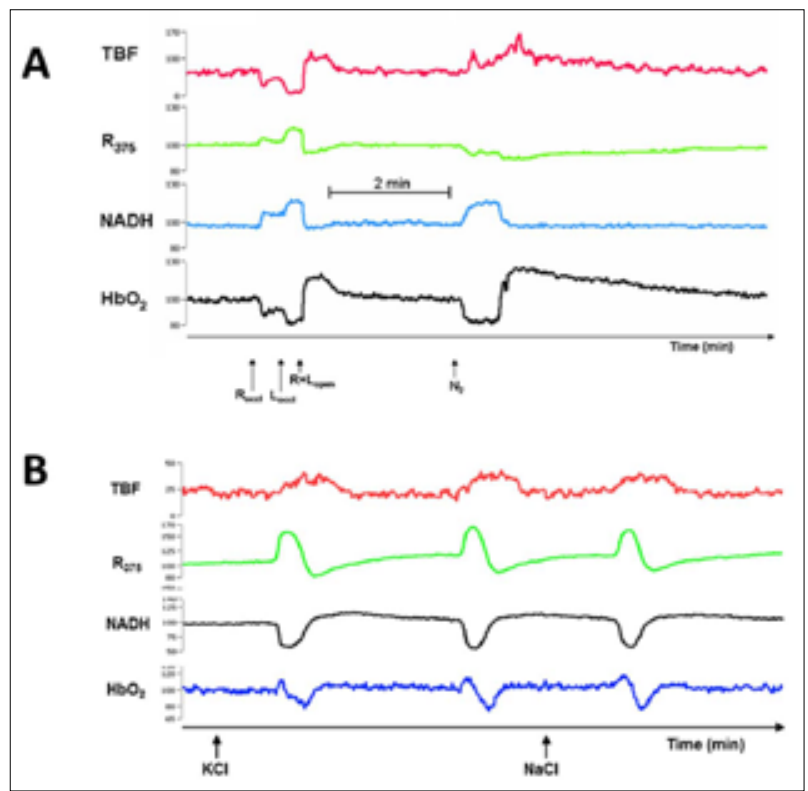

Figure 21: A - The effects of ischemia (left) and anoxia (right) on the 4 parameters measured from the brain of an anesthetized Gerbil using the developed medical device. $\mathrm{N}_{2}-100 \%$ Nitrogen, R+Loccl - Occlusion of the right and left common carotid artery, TBF - tissue blood flow, $\mathrm{R}_{375}$ - reflected light at the excitation wavelength of NADH $(375 \mathrm{~nm}), \mathrm{NADH}-$ Corrected fluorescence, $\mathrm{HbO}_{2}$ - Relative levels of hemoglobin oxygenation.

B - Effect of Cortical spreading depression induced by epidural application of concentrated $\mathrm{KCl}$ solution.

Under anoxia $\left(100 \% \mathrm{~N}_{2}\right)$ the initial response was the decrease in $\mathrm{HbO}_{2}$ followed by an increase in NADH (right side) The TBF showed a later increase which turned into a hyperemic response that was also recorded in the $\mathrm{HbO}_{2}$ signal after the recovery from anoxia.

The effects of Cortical Spreading Depression-CSD is shown in Figure 21B. Due to the process of brain activation the NADH decreased indication of increase in ATP production. Due to the increase in oxygen consumption, the cerebral blood flow (TBF) increased and the $\mathrm{HbO}_{2}$ shows a biphasic response starting with a small decreased followed by a large decrease.

\section{Testing the new medical device (NMD) in patients}

We tested the hypothesis that the urethral wall's mitochondrial function and microcirculatory blood flow in patients would be sensitive to macro-circulatory changes taking place during cardiovascular surgery. We chose this sample because of its existing invasive monitoring and the known alterations in the microcirculatory blood flow produced by surgery. In a group of five patients we tested the responsiveness of the urethral wall to a clear local event of ischemia achieved by the clamping of the abdominal aorta. During this phase of the operation, the microcirculatory blood flow in the urethra decreased in all patients, while the results of NADH measurements showed some variability. Typical responses to aortic occlusion in one of the AAA patients are shown in Figure 22.

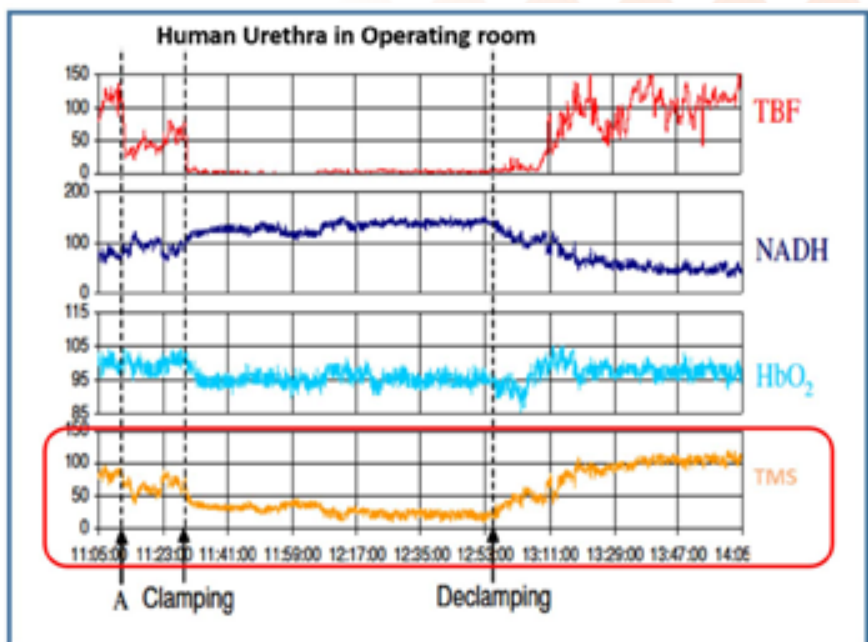

Figure 22: Effects of aortic occlusion in a patient that underwent an abdominal aortic aneurysm (AAA) repair operation, on the 3 parameters monitored by the developed medical device. The technical preparation for aortic occlusion was performed at the marker A. The forth parameter is the score - Tissue Metabolic

Score (TMS) calculated from the monitored parameters.

The clamping of the aorta led to a maximal decrease in $\mathrm{TBF}$ in parallel to the increase in NADH. In this patient, the monitored $\mathrm{HbO}_{2}$ showed a clear decrease during the clamping interval. Due to a decrease in tissue blood volume, during the aortic occlusion, the reflectance trace showed a large increase until the reopening of the occluded aorta. Immediately after de-clamping, the initial small increase in TBF led to a fast recovery of the $\mathrm{HbO}_{2}$ and NADH redox state. All signals recovered to the same values measured during the short control period, although the occlusion interval lasted for more than 80 minutes. The lowest trace shows the calculated TMS measured from the urethra.

Figure $23 \mathrm{~A}, \mathrm{~B}$ presents the results measured in two patients during heart bypass surgeries [79]. The monitoring of the various parameters was performed using a three way Foley catheter inserted into the urethra. In the first patient shown in Figure 23A, the responses of TBF and NADH were recorded as soon as the preparation for operation started with the scrubbing of the chest area. The low level of TBF and the high level of $\mathrm{NADH}$ were recorded during the entire operation procedure and the recovery began as soon as the chest was closed. When the patient left the operating room for the cardiac ICU, the 2 parameters were close to the baseline levels. In the second patient operated for aortic repair (Fig. 23B), clear responses to the procedure were recorded. In this patient, the initiation of extracorporeal circulation led to a large decrease in TBF and a large increase in NADH. The signals reverted toward the initial values, although the baseline was not reached. The calculated index (in green line) was calculated in the two patients and shows the dominant parameter affecting the index J B \& Bio Engine; $2020 \quad$ www.unisciencepub.com Volume 1 | Issue 3 
is the mitochondrial NADH.

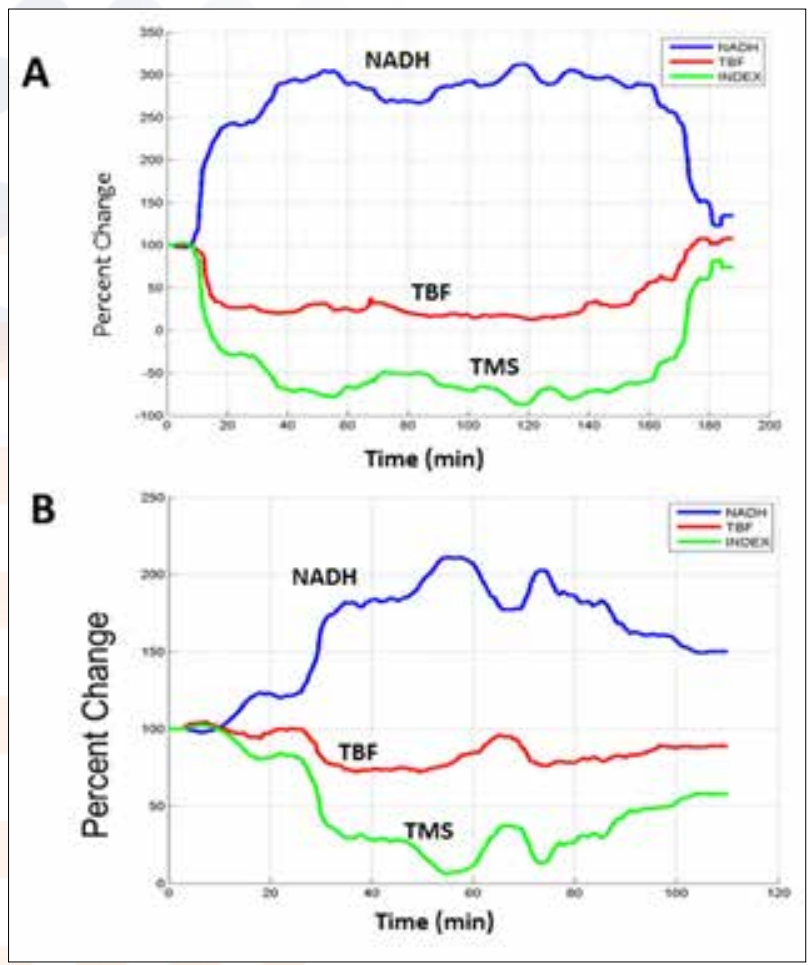

Figure 23: A-B The effects of the surgical procedure, in 2 cardiovascular operated patients, on the urethral TBF and NADH redox state (see text for detailed explanations). The Index in green - Tissue Metabolic Score (TMS) calculated from the monitored parameters.

\section{Discussion}

As presented in the current paper, monitoring of patients in critical conditions, such as ARDS and COVID-19, could be divided into two categories as seen in Figure 4. The dominant approach is to monitor physiological parameters relevant to the functions of the respiratory and cardiovascular systems. This group of parameters includes respiratory rate, heart rate, systemic blood pressure, systemic hemoglobin saturation and core temperature. Using this approach, the clinicians defined those parameters as being the "vital signs" for patient's assessing in real time [86-88]. The 2nd approach that could be used in patient's monitoring is to measure parameters that represent the activity of the microcirculatory and intracellular compartment such as cellular respiration and mitochondrial function. This approach was not developed to a stage of daily usage by clinician in patients' monitoring. We were able to develop such a device as described in the previous 3 sections.

One of the main problems in COVID-19 and ARDS patients is the disturbances in keeping the oxygen homeostasis in the body. The main issue is to determine and select the best parameter that can help the clinician to check the status of the oxygen homeostasis. The sole available information for this pathophysiology developed is the decrease in systemic hemoglobin saturation as measured by the pulse oximeter. As shown in Figure 6 this parameter represents the availability of oxygen in the macro circulation but not in the microcirculation which is the immediate supply of oxygen to the intracellular organelle - the mitochondria. In pulse oximetry, the output of the device is related only to the oxygen saturation in the pulsatile arteries and not in the microcirculation.

For research purposes it's possible to measure various factors that are part of the molecular physiology and pathophysiology at the cellular oxygen metabolism level, i.e. hypoxia inducible factors (HIF) as described by Samanta et al., [89]. Unfortunately, those techniques are not adaptable to real time in vivo monitoring of patients. Therefore, we have to use other parameters for patient monitoring as seen in Figures 1, 2 and 4. As of today, the monitoring of the respiratory and macrocardiovascular systems is well establish as presented in Figure 4. In addition to the measurements of up to 8 parameters that could be identified as vital signs, few groups developed a scoring systems that are based on the measured vital signs [86,88,90-95].

It's important to note that until now the clinical system to monitor patients is missing any kind of accepted technology that provide reliable data on the microcirculation and cellular mitochondrial function. As demonstrated in the introduction section most of the consumed oxygen by the body is utilized by the cytochrome oxidase being part of the oxidative phosphorylation system in the mitochondria. Therefore, monitoring of the mitochondrial redox state is the only way to evaluate tissue oxygen consumption under in vivo conditions. An indirect technique to evaluate oxygen metabolism at the tissue level is to measure the saturation of hemoglobin in the microcirculation as well as to measure the partial pressure of oxygen in the tissue using microelectrode or surface electrode as discussed in the introduction section. All those techniques are very sensitive to changes in tissue blood flow and under many situations a hyperemic response will be recorded after ischemia or hypoxia depending on the monitored organ. This response is mainly due to a large increase in blood flow in the brain for example and not due to a large change in oxygen consumption.

As seen in Figure 1 and 3 the best way to record and evaluate tissue oxygen homeostasis is to switch from a single measured parameter to a multiparametric monitoring approach. Our aim was to develop a multiparametric monitoring system that will measure various parameters in the microcirculation in addition to the evaluation in real time the intracellular function of the mitochondria. Beside the technological development and integration, we developed an algorithm that calculate in real time the "LifenLight Score" (LLS) based on the 4 monitored parameters. The previous name of this score was Tissue Metabolic Score or Brain Metabolic Score. The dominant parameter that affect the LLS is the redox state of the mitochondrial NADH. It contributes $70-80 \%$ to the calculated LLS as compared to $20-30 \%$ contributed by the other parameters that represent the microcirculation events. 
The monitoring of the $\mathrm{Hb}$ saturation by the pulse oximetry is very limited in its contribution to the evaluation of the efficacy of adding to the patient higher level of oxygen in the breathing mixture. As we mentioned in previous sections, the level of $\mathrm{Hb}$ oxygenation or saturation in the microcirculation, under normal conditions, is relatively lower compared to the pulse oximetry levels (see Fig. 4A). According to a leading research and clinicians, the microcirculation is the terminal micro vessels having diameter smaller than 20 microns and therefore it's clear that they are not contributing to the pulse oximetry measured signal [96]. Also, described in details the fact that the pulse oximetry signal is originated from the pulsatile arterial blood without any contribution of the non-pulsatile arterioles and capillaries $[96,97]$. Few years ago, Jonasson et al developed a new technique to monitor microcirculatory hemoglobin saturation and perfusion simultaneously [98]. Let assume that in Covid-19 or ARDS patients the pulse oximetry values will drop to $85-90 \%$ and the treatment will be an increase in oxygen supply to $95 \%$. The question will be what will be the saturation in the microcirculation after the treatment. To get the answer, it's necessary to monitor the saturation in the microcirculation or the mitochondrial NADH redox state.

Also, in part of the patients the pulse oximetry device will present a saturation level of $95 \%$ but at the same time the $\mathrm{Hb}$ oxygenation at the very end capillaries will be very low due to local vasoconstriction of the small arterioles [99]. Under these conditions the local microcirculatory level of $\mathrm{Hb}$ oxygenation measured by the developed new device will be sensitive to the local changes in the $\mathrm{Hb}$ oxygenation. In addition, by monitoring of the mitochondrial NADH redox state will be sensitive to local events occurred in the microcirculation and will show the real situation in the power - house of the cells, the mitochondria.

The results of our preliminary monitoring of patients were published and indicated that our approach is feasible and need further studies [79]. The location of the sensing elements in the urethra is a very promising approach that will also allow us to add more parameters to be monitored from the same location.

Conflicts of Interest: The authors declare no conflict of interest

\section{References}

1. Wu F., S. Zhao, B. Yu, Y. M. Chen, W. Wang, Z. G. Song, Y. Hu, et al. (2020) A new coronavirus associated with human respiratory disease in China. Nature 579: 265-269.

2. Huang C, Y Wang, X Li, L Ren, J Zhao, Y Hu, L Zhang, et al. (2020) Clinical features of patients infected with 2019 novel coronavirus in Wuhan, China. Lancet 395: 497-506.

3. Geier MR, DA Geier (2020) Respiratory conditions in coronavirus disease 2019 (COVID-19): Important considerations regarding novel treatment strategies to reduce mortality. Med. Hypotheses 140: 109760.

4. Lutje S, M Marinova, D Kutting, U Attenberger, M Essler, RA Bundschuh (2020) Nuclear medicine in SARS-CoV-2 pandemia: 18F-FDG-PET/CT to visualize COVID-19. Nuklearmedizin 59: 276-280.

5. Xu Z., L. Shi, Y. Wang, J. Zhang, L. Huang, C. Zhang, S. Liu, et al. (2020) Pathological findings of COVID-19 associated with acute respiratory distress syndrome. Lancet Respir. Med 8: 420-422.

6. Varga Z, A. J. Flammer, P. Steiger, M. Haberecker, R. Andermatt, A. S. Zinkernagel, M. R. Mehra, et al. (2020) Endothelial cell infection and endotheliitis in COVID-19. Lancet 395: 1417-1418.

7. Ashbaugh DG, DB Bigelow, TL Petty, BE Levine (1967) Acute respiratory distress in adults. Lancet 2:319-323.

8. Fanelli V, A Vlachou, S Ghannadian, U Simonetti, AS Slutsky, H Zhang (2013) Acute respiratory distress syndrome: new definition, current and future therapeutic options. J. Thorac. Dis 5: 326-334.

9. Rawal G., S. Yadav, R. Kumar (2018) Acute respiratory distress syndrome: An update and review. J. Transl. Int. Med 6: 74-77.

10. Spinelli E, T. Mauri, J. R. Beitler, A. Pesenti, D. Brodie (2020) Respiratory drive in the acute respiratory distress syndrome: pathophysiology, monitoring, and therapeutic interventions. Intensive Care Med 46: 606-618.

11. Wang M., Y. Zhou, Z. Zong, Z. Liang, Y. Cao, H. Tang, B. Song, et al (2020) A precision medicine approach to managing 2019 novel coronavirus pneumonia. Precis. Clin. Med 3: 14-21.

12. Altmann R (1890) Die Elementarorganismen Und Ihre Beziehungen Zu Den Zellen. Veit \& comp, Leipzig.

13. Benda C (1898) Ueber die Spermatogenese der Vertebraten und höherer Evertebraten, II. Theil: Die Histiogenese der Spermien. Arch. Anat. Physiol 73: 393-398.

14. Jobsis FF (1964) Basic processes in cellular respiration. in Fenn and Rabn, editors. Handbook of Physiology Respiration 63-124.

15. Mason H. S (1957) Mechanisms of oxygen metabolism. Adv Enzymol Relat Subj Biochem 19: 79-233

16. Pereira M. M, M. Santana, M. Teixeira (2001) A novel scenario for the evolution of haem-copper oxygen reductases. Biochim. Biophys. Acta 1505: 185-208.

17. Waltemath CL (1970) Oxygen, uptake, transport, and tissue utilization. Anesth. Analg 49: 184-203.

18. Wikstrom M., K. Krab, V. Sharma (2018) Oxygen activation and energy conservation by Cytochrome c oxidase. Chem. Rev 118: 2469-2490.

19. Mayevsky A, B Sjoquist, C. G. Fri, D. Samuel, G. Sedvall (1973) Incorporation of $18 \mathrm{O}$ into homovanillic acid of rat brain during exposure to oxygen 18 containing atmospheres. Biochem. Biophys. Res. Commun 51: 746755.

20. Stansfield D. A, R. G. Stansfield (1986) Dr Thomas Beddoes and James Watt: preparatory work 1794-96 for the Bristol Pneumatic Institute. Med. Hist 30: 276-302.

21. Cannon WB (1929) Organization for physiological homeostasis. Physio. Rev 9: 399-430.

22. Bernard C (1878) Lions on the phonomones of communicating with animators and auxiliaries

23. Roy C. S, C. S. Sherrington (1890) On the regulation of 
the blood-supply of the brain. J. Physiol 11: 85-158 117.

24. Barcroft J (1914) The Respiratory Function of Blood. Cambridge University Press, Cambridge.

25. Branson RD, BR Robinson (2011) Oxygen: when is more the enemy of good? Intensive Care Med 37: 1-3.

26. Martin D. S, M. P. Grocott (2013) III. Oxygen therapy in anaesthesia: the yin and yang of $\mathrm{O} 2$. Br. J. Anaesth 111: 867-871.

27. Mayevsky, A (1992) Cerebral blood flow and brain mitochondrial redox state responses to various perturbations in gerbils. Adv. Exp. Med. Biol 317: 707716.

28. Rampil I. J, L. Litt, A. Mayevsky (1992) Correlated, simultaneous, multiple-wavelength optical monitoring in vivo of localized cerebrocortical $\mathrm{NADH}$ and brain microvessel hemoglobin oxygen saturation. J. Clin. Monit 8: $216-225$.

29. Warburg O (1949) Heavy Metal Prosthetic Groups and Enzyme Action.in T. A. Lawson, editor. Clarendon Press, Oxford.

30. Keilin D (1925) On cytochrome, a respiratory pigment, common to animals, yeast, and higher plants. Proc. R. Soc. Lond. B. Biol. Sci 98: 312-339.

31. Chance B (1952) Spectra and reaction kinetics of respiratory pigments of homogenized and intact cells. Nature 169: 215-221.

32. Chance B (1953) Dynamics of respiratory pigments of ascites tumor cells. Trans. N.Y. Acad. Sci 16: 74-75.

33. Theorell H, R. Bonnichsen (1951) Studies on liver alcohol dehydrogenase I. Equilibria and initial reaction velocities. Acta Chem. Scand 5: 1105-1126.

34. Theorell H, B. Chance (1951) Studies on liver alcohol dehydrogenase II. The kinetics of the compound of horse liver alcohol dehydrogenase and reduced diphosphopyridine nucleotide. Acta Chem. Scand 5: 1127-1144.

35. Chance B, H Baltscheffsky (1958) Respiratory enzymes in oxidative phosphorylation (VII - Binding of intramitochondrial reduced pyridine nucleotide). J. Biol. Chem 233: 736-739.

36. Duysens LNM, J Amesz (1957) Fluorescence spectrophotometry of reduced phosphopyridine nucleotide in intact cells in the near-ultraviolet and visible region. Biochim. Biophys. Acta 24: 19-26.

37. Chance B, GR Williams (1955d) Respiratory enzymes in oxidative phosphorylation (I- Kinetics of oxygen utilization). J. Biol. Chem 217: 383-393.

38. Chance B, GR Williams (1955c) Respiratory enzymes in oxidative phosphorylation (II- Difference spectra). J. Biol. Chem 217: 395-407.

39. Chance B, GR Williams (1955b) Respiratory enzymes in oxidative phosphorylation (III- The steady state). J. Biol. Chem 217: 409-427.

40. Chance B, GR Williams (1955a) Respiratory enzymes in oxidative phosphorylation (IV- The respiratory chain). J. Biol. Chem 217: 429-438.

41. Chance B, GR Williams, WF Holmes, J Higgins (1955) Respiratory enzymes in oxidative phosphorylation (V-A mechanism for oxidative phosphorylation). J. Biol. Chem
217: 439-451.

42. Chance B, GR Williams (1956) The respiratory chain and oxidative phosphorylation. F. F. Nord, editor. Advances in Enzymology. Interscience Publisher, Inc., New York 65134.

43. Chance B, P Cohen, F Jobsis, B Schoener (1962a) Intracellular oxidation-reduction states in vivo. Science 137: 499-508.

44. Chance B, V Legallias, B Schoener (1962b) Metabolically linked changes in fluorescence emission spectra of cortex of rat brain, kidney and adrenal gland. Nature 195: 10731075.

45. Chance B, B Schoener (1962) Correlation of oxidationreduction changes of intracellular reduced pyridine nucleotide and changes in electro-encephalogram of the rat in anoxia. Nature 195: 956-958.

46. Chance B, B Schoener, JJ Fergusson (1962c) In vivo induced oxidation by adrenocorticotrophic hormone of reduced pyridine nucleotide in the adrenal cortex of hypophysectomized rats. Nature 195: 776-778.

47. Blinks LR, RK Skow (1938) The time course of photosynthesis as shown by a rapid electrode method for oxygen. Proc. Natl. Acad. Sci U.S.A. 24: 420-427.

48. Cater DB, IA Silver (1960) Quantitative measurements of oxygen tension in normal tissues and in the tumours of patients before and after radiotherapy. Acta Radiol 53: 233-256.

49. Davies PW (1942) Microelectrodes for measuring local oxygen tension in animal tissues. Review of Scientific Instruments 13: 524.

50. Bronk DW (1946) The physical structure and biological action of nerve cells: with some references to the problems of human flight. Am. Sci 34: 54-76.

51. De Santis V, d M Singer (2015) Tissue oxygen tension monitoring of organ perfusion: rationale, methodologies, and literature review. Br. J. Anaesth 115: 357-365.

52. Ortiz-Prado E., J. F. Dunn, J. Vasconez, D. Castillo, G. Viscor (2019) Partial pressure of oxygen in the human body: a general review. Am. J. Blood Res 9: 1-14.

53. Zauner A., E. Doppenberg J. J. Woodward, C. Allen, S. Jebraili, H. F. Young, R. Bullock (1997) Multiparametric continuous monitoring of brain metabolism and substrate delivery in neurosurgical patients. Neurol. Res 19: 265273.

54. Mayevsky A (1983) Multiparameter monitoring of the awake brain under hyperbaric oxygenation. J. Appl. Physiol 54: 740-748.

55. Mayevsky A, W Crowe, L. Mela (1980) The interrelation between brain oxidative metabolism and extracellular potassium in the unanesthetized gerbil. Neurol. Res 1: 213-226.

56. Mayevsky A, D. S. Sclarsky (1983) Correlation of brain NADH redox state, $\mathrm{K}+, \mathrm{PO} 2$ and electrical activity during hypoxia, ischemia and spreading depression. Adv. Exp. Med. Biol 159: 129-141.

57. Mayevsky A, B. Chance (1975) Metabolic responses of the awake cerebral cortex to anoxia hypoxia spreading depression and epileptiform activity. Brain Res 98: 149165. 
58. Tsai A. G, P. C. Johnson, M. Intaglietta (2003) Oxygen gradients in the microcirculation. Physiol. Rev 83: 933963.

59. Roy C. S (1881) The elastic properties of the arterial wall. J. Physiol 3: 125-159.

60. Hertzman AB (1937) Photoelectric plethysmography of the fingers and toes in man. Proc. Soc. Exp. Biol. Med 37: 529-542.

61. Hertzman AB (1938) The blood supply of various skin areas as estimated by the photoelectric plethysmograph. Am. J. Physiol 124: 328-340.

62. Allen J (2007) Photoplethysmography and its application in clinical physiological measurement. Physiol. Meas. 28: R1-39.

63. Aoyagi T, M Kiahi, K Yamaguchi, S Watanabe (1974) Improvement of the earpiece oximeter. Abstracts of the 13th Annual Meeting of the Japanese Society of Medical Electronics and Biological Engineering: 90-91.

64. Aoyagi T, K Miyasaka (2002) Pulse oximetry: its invention, contribution to medicine, and future tasks. Anesth. Analg 94: S1-3.

65. Nitzan M., A. Romem, R. Koppel (2014) Pulse oximetry: fundamentals and technology update. Med. Devices (Auckl) 7: 231-239.

66. Severinghaus J. W, Y. Honda (1987) History of blood gas analysis. VII. Pulse oximetry. J. Clin. Monit 3: 135-138.

67. Shelley K. H (2007) Photoplethysmography: beyond the calculation of arterial oxygen saturation and heart rate. Anesth. Analg 105: S31-36.

68. Yoshiya I., Y. Shimada, K. Tanaka (1980) Spectrophotometric monitoring of arterial oxygen saturation in the fingertip. Med. Biol. Eng. Comput 18: 27-32.

69. Scheeren T. W. L, F. J. Belda, A. Perel (2018) The oxygen reserve index (ORI): a new tool to monitor oxygen therapy. J. Clin. Monit. Comput 32: 379-389.

70. Frank KH, M Kessler, K Appelbaum, W Dummler (1989) The Erlangen micro-lightguide spectrophotometer EMPHO I. Phys. Med. Biol 34: 1883-1900.

71. Mayevsky A., E. S. Flamm, W. Pennie, B. Chance (1991) A fiber optic based multiprobes system for intraoperative monitoring of brain functions. SPIE 1431: 303-313.

72. Mayevsky A., K. Frank M. Muck, S. Nioka, M. Kessler, B. Chance (1992) Multiparametric evaluation of brain functions in the Mongolian gerbil in vivo. J. Basic Clin. Physiol. Pharmacol 3: 323-342.

73. Mayevsky A, K. H. Frank, S. Nioka, M. Kessler, B. Chance (1990) Oxygen supply and brain function in vivo: a multiparametric monitoring approach in the Mongolian gerbil. Adv. Exp. Med. Biol 277: 303-313.

74. Mayevsky A, S. Cohen (1990) Brain ischemic depolarization and vasospasm in the Mongolian gerbil: The dependence on energy depletion levels. Adv. Exp. Med. Biol 277: 315-322.

75. Meirovithz E, J. Sonn, A. Mayevsky (2007) Effect of hyperbaric oxygenation on brain hemodynamics, hemoglobin oxygenation and mitochondrial NADH. Brain Res. Rev 54: 294-304.

76. Deutsch A, E Pevzner, A Jaronkin, A Mayevsky (2004)
Real time evaluation of tissue vitality by monitoring of microcircultory blood flow, $\mathrm{HbO} 2$ and mitochondrial NADH redox state. SPIE Proceedings 5317: 116127.

77. Mayevsky A, A. Deutsch, N. Dekel, E. Pevzner, A. Jaronkin (2005) A new biomedical device for in vivo multiparametric evaluation of tissue vitality in critical care medicine. Proc. SPIE 5692: 60-70.

78. Kutai-Asis H, E Barbiro-Michaely, A Deutsch, A Mayevsky (2006) Fiber optic based multiparametric spectroscopy in vivo: Toward a new quantitative tissue vitality index. SPIE Proc 6083: 10-11-10-10

79. Mayevsky A, R. Walden, E. Pewzner, A. Deutsch, E. Heldenberg, J. Lavee, S. Tager, et al. (2011) Mitochondrial function and tissue vitality: bench-to-bedside real-time optical monitoring system. J. Biomed. Optics 16: 067004 067001-067021.

80. Mayevsky A (1978) Ischemia in the brain: The effects of carotid artery ligation and decapitation on the energy state of the awake and anesthetized rat. Brain Res 140: 217230.

81. Rosenthal M, D. L. Martel (1979) Ischemia-induced alterations in oxidative "recovery" metabolism after spreading cortical depression in situ. Exp. Neurol 63: 367378.

82. Mayevsky A., A. Doron, T. Manor, S. Meilin, N. Zarchin, G. E. Ouaknine (1996) Cortical spreading depression recorded from the human brain using a multiparametric monitoring system. Brain Res 740: 268-274.

83. Barbiro-Michaely E, M Tolmasov, S Rinkevich-Shop, J Sonn, A Mayevsky (2007) Can the "brain-sparing effect" be detected in a small-animal model? Med Sci Monit 13: Br211-219.

84. Ekbal NJ, A Dyson, C Black, M Singer (2013) Monitoring tissue perfusion, oxygenation, and metabolism in critically ill patients. Chest 143: 1799-1808.

85. Dyson A, M Singer (2011) Tissue oxygen tension monitoring: will it fill the void? Curr. Opin. Crit. Care 17: 281-289.

86. Elliott M, A Coventry (2012) Critical care: The eight vital signs of patient monitoring. Br. J. Nursing 21: 621-625.

87. Santos MD (2018) Vital-Sign Data-Fusion Methods to Identify Patient Deterioration in the Emergency Department. Doctor of Philosophy. St Hilda's College University of Oxford, University of Oxford.

88. Santos M. D, D. A. Clifton, L. Tarassenko (2014) Performance of early warning scoring systems to detect patient deterioration in the emergency department. Pages 159-169 in J. Gibbons and W. MacCaull, editors. FHIES 2013. Foundations of Health Information Engineering and Systems. Lecture Notes in Computer Science. Springer, Berlin, Heidelberg.

89. Samanta D., N. R. Prabhakar, G. L. Semenza (2017) Systems biology of oxygen homeostasis. Wiley Interdiscip. Rev. Syst. Biol. Med 9.

90. Bonnici T, S Gerry, D Wong, J Knight, P Watkinson (2016) Evaluation of the effects of implementing an electronic early warning score system: protocol for a stepped wedge study. BMC Med. Inform. Decis. Mak 16: 19. 
91. Clifton DA, D Wong, L Clifton, S Wilson, R Way, R Pullinger, L Tarassenko (2013) A large-scale clinical validation of an integrated monitoring system in the emergency department. IEEE J Biomed Health Inform 17: 835-842.

92. Malycha J, N Farajidavar, MAF Pimentel, O Redfern, D. A. Clifton, L. Tarassenko, P. Meredith, et al. 2019. The effect of fractional inspired oxygen concentration on early warning score performance: A database analysis. Resuscitation 139: 192-199.

93. Tarassenko L., D. A. Clifton, M. R. Pinsky, M. T. Hravnak, J. R. Woods, P. J. Watkinson (2011) Centile-based early warning scores derived from statistical distributions of vital signs. Resuscitation 82: 1013-1018.

94. Trubey R., C. Huang F. V. Lugg-Widger, K. Hood, D. Allen, D. Edwards, D. Lacy, et al. (2019) Validity and effectiveness of paediatric early warning systems and track and trigger tools for identifying and reducing clinical deterioration in hospitalised children: a systematic review. BMJ Open 9: e022105.

95. Wuytack F, P. Meskell, A. Conway, F. McDaid, N. Santesso, F. G. Hickey, P. Gillespie, et al (2017) The effectiveness of physiologically based early warning or track and trigger systems after triage in adult patients presenting to emergency departments: a systematic review. BMC Emergency Medicine 17: 38.

96. Guven G, MP Hilty, C Ince (2020) Microcirculation: Physiology, Pathophysiology, and Clinical Application. Blood Purif 49: 143-150.

97. Chan ED, MM Chan (2013) Pulse oximetry: understanding its basic principles facilitates appreciation of its limitations. Respir. Med 107: 789-799.

98. Jonasson H, I Fredriksson, A Pettersson, M Larsson, T Stromberg (2015) Oxygen saturation, red blood cell tissue fraction and speed resolved perfusion - A new optical method for microcirculatory assessment. Microvasc. Res 102: 70-77.

99. Moore J. P, A. Dyson, M. Singer, J. Fraser (2015) Microcirculatory dysfunction and resuscitation: why, when, and how. Br. J. Anaesth 115: 366-375.

100.Fan E, Brodie D, Slutsky AS. (2018) Acute Respiratory Distress Syndrome: Advances in Diagnosis and Treatment. JAMA.;319(7):698-710.

101. Chance, B., N. Oshino, T. Sugano, and A. Mayevsky. (1973). Basic principles of tissue oxygen determination from mitochondrial signals. Adv. Exp. Med. Biol., 37A:277-292.

Copyright: (C2020 Avraham Mayevsky. This is an open-access article distributed under the terms of the Creative Commons Attribution License, which permits unrestricted use, distribution, and reproduction in any medium, provided the original author and source are credited. 